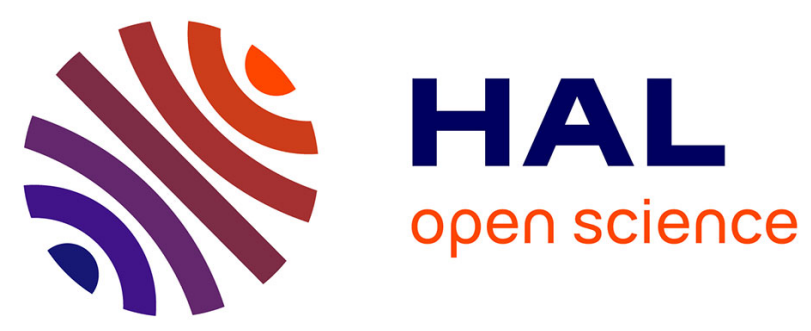

\title{
International Stock Return Predictability: Evidence from New Statistical Tests
}

\author{
Amélie Charles, Olivier Darné, Jae H Kim
}

\section{To cite this version:}

Amélie Charles, Olivier Darné, Jae H Kim. International Stock Return Predictability: Evidence from New Statistical Tests. International Review of Financial Analysis, 2017, 54, pp.97-113. hal-01626101

\section{HAL Id: hal-01626101 \\ https://hal-audencia.archives-ouvertes.fr/hal-01626101}

Submitted on 30 Oct 2017

HAL is a multi-disciplinary open access archive for the deposit and dissemination of scientific research documents, whether they are published or not. The documents may come from teaching and research institutions in France or abroad, or from public or private research centers.
L'archive ouverte pluridisciplinaire HAL, est destinée au dépôt et à la diffusion de documents scientifiques de niveau recherche, publiés ou non, émanant des établissements d'enseignement et de recherche français ou étrangers, des laboratoires publics ou privés. 


\title{
International Stock Return Predictability: Evidence from New Statistical Tests
}

\author{
Amélie CHARLES* \\ Audencia Business School \\ Olivier DARNÉ ${ }^{\dagger \ddagger}$ \\ LEMNA, University of Nantes \\ Jae H. KIM ${ }^{\S}$ \\ Department of Finance, La Trobe University
}

\begin{abstract}
We investigate whether stock returns of international markets are predictable from a range of fundamentals including key financial ratios (dividend-price ratio, dividendyield, earnings-price ratio, dividend-payout ratio), technical indicators (price pressure, change in volume), and short-term interest rates. We adopt two new alternative testing and estimation methods: the improved augmented regression method and wild bootstrapping of predictive model based on a restricted VAR form. Both
\end{abstract}

*Audencia Business School of Management, 8 route de la Jonelire, 44312 Nantes, France. Email: acharles@audencia.com.

${ }^{\dagger}$ LEMNA, University of Nantes, IEMN-IAE, Chemin de la Censive du Tertre, BP 52231, 44322 Nantes, France. Email: olivier.darne@univ-nantes.fr.

$\ddagger$ Olivier Darné gratefully acknowledge financial support from the Chaire Finance of the University of Nantes Research Foundation.

${ }^{\S}$ Corresponding Author: J.Kim@latrobe.edu.au; All computations are conducted using the VAR.etp package (Kim, 2014c) based on $\mathrm{R}$ ( $\mathrm{R}$ Core team, 2014). The $\mathrm{R}$ codes used in this paper are available from the authors on request. 
methods take explicit account of endogeneity of predictors, providing bias-reduced estimation and improved statistical inference in small samples. From monthly data of 16 Asia-Pacific (including U.S.) and 21 European stock markets from 2000 to 2014, we find that the financial ratios show weak predictive ability with small effect sizes and poor out-of-sample forecasting performances. In contrast, the price pressure and interest rate are found to be strong predictors for stock return with large effect sizes and satisfactory out-of-sample forecasting performance.

Keywords: Augmented Regression Method, Financial ratios, Forecasting, Technical indicators, Wild bootstrap.

JEL Classification: G12, G14. 


\section{Introduction}

Whether stock return is predictable from an economic fundamental has been an issue of much interest and contention in empirical finance. Notable recent contributions include Cochrane (2008), Lettau and Van Nieuwerburgh (2008), Welch and Goyal (2007), and Ang and Bekaert (2007). The accumulated empirical evidence is extensive, but the consensus on the predictability of stock return is rather weak. Some authors believe that key financial indicators have ability to predict stock return (e.g., Lettau and Ludvigson, 2001; p.942), while others have found mixed and conflicting results (e.g., Welch and Goyal, 2007; p.1455). While the studies for the U.S. market dominate the extant literature, the case of non-U.S markets has received attention only recently: see Wohar et al. (2005), Schrimpf (2008), Hjarmarsson (2010), Giot and Petitjean (2011), and Jordan et al. (2014). On the other hand, using the U.S. data, Neely et al. (2014) provide evidence that technical indicators show much stronger ability to predict stock return than financial ratios.

An important methodological issue in the literature of predictive regression is the Stambaugh (1999) bias. It occurs when a predictor is treated as exogenous to stock return, while it is in fact endogenous. That is, a shock to the predictor is often strongly correlated with that of stock return. Ignoring this endogeneity causes an upward bias in the estimation of predictive coefficients in small samples. As discussed in Lewellen (2004) and Cochrane (2008), this upward bias can lead to a serious over-statement of predictability and spurious rejection of the null hypothesis of no return predictability. This is particularly so when the predictor is persistent and the degree of endogeneity is high, which are the typical features of popular predictors such as the dividend-yield. ${ }^{1}$ To mitigate the Stambaugh bias and conduct bias-corrected estimation and statistical inference, Amihud et al. (2009, 2010) propose the augmented regression method (ARM), which is modified by Kim (2014a) for improved small sample properties and implementation. Amihud et al. (2010) and Kim (2014a) apply their methods to the U.S. stock returns and report the evidence that the dividend-yield shows little predictability for stock return, in contrast with the past results which show strong predictability.

While several studies have assessed the predictability of stock return of inter-

\footnotetext{
${ }^{1}$ It is well documented that most variables employed in predictive regressions are highly persistent with autoregressive roots extremely close to unity (see, e.g., Cavanagh et al., 1995; Campbell and Yogo, 2006; Kostakis et al., 2015).
} 
national markets, they have adopted different models and methods. Wohar et al. (2005) and Jordan et al. (2014a) examine the return predictability of a number of European and international stock markets, but their predictive regression treats the predictor variable exogenously. Hjarmarsson (2010) uses the panel regression methods for the stock returns of a large number of global markets, adopting a pooled estimation method which provide estimation and testing outcomes free from the Stambaugh bias. Schrimpf (2010), adopting the ARM of Amihud et al. (2009), reports that the return predictability of international stock markets are not uniform across countries. Neely et al. (2014) assess the predictive ability of technical indicators, but based on the predictive regression without making the adjustment for Stambaugh bias. All of these past studies set the lag order of predictive model to one, which may be subject to model specification bias.

This paper is a fresh and comprehensive study for the return predictability of international stock markets. Using monthly data from 2000 to 2014 for 16 AsiaPacific and 21 European markets, we examine the predictive ability of financial ratios (dividend-price ratio, dividend-yield, earnings-price ratio, dividend-payout ratio), technical indicators (price pressure, change in volume), and short-term interest rates. In addition to the improved ARM of Kim (2014a), we employ a wild bootstrap test based on a restricted vector autoregressive (VAR) form of predictive model for stock return. The latter is a non-parametric (based on data resampling) alternative to the former, providing statistical inference robust to non-normality and (conditional) heteroskedasticity. We note that these two methods show highly desirable small sample properties (see Kim and Shamsuddin, 2014), and can be implemented to a predictive model with a general lag order higher than one.

Our study finds that all financial ratios appear to be weak predictors for stock return, with poor in-sample and out-of-sample performances. In contrast, the price pressure (a momentum indicator) is found to be a strong predictor for nearly all stock markets, with large effect sizes and accurate out-of-sample forecasts. In addition, the short-term interest appears to be a strong predictor, both in-sample and out-of-sample, especially for European stock markets. In the next section, we present a brief survey of past empirical studies on stock return predictability for international (non-U.S.) stock markets. Section 3 presents the data details, and Section 4 the methodologies. Section 5 presents the empirical results, and Section 6 concludes the paper. 


\section{Literature Review}

Despite a large number of studies on stock return predictability for the US stock market, the existing literature on the predictability of stock return of non-US markets, including those of Asia-Pacific and Europe, has not been extensive. Since the studies on the U.S. market are well-documented in the literature, we provide a list of the studies for the non-U.S. markets: see Table 1 for a review of selected studies on the stock return predictability in Asia-Pacific and Europe.

Bossaerts and Hillion (1999) investigate the predictability of excess stock return for 14 countries, using four predictors (dividend-price ratio; earnings-price ratio; and short-term and long-term interest rates) covering the period 1956-1995. ${ }^{2}$ They select the best predictive regression models from seven model selection criteria, with some are robust to non-stationary predictors. They find evidence of in-sample predictability but no out-of-sample predictability. Hjarmarsson (2010) adopts the panel regression methods for the stock returns from 40 international markets, including 24 developed and 16 emerging economies, using four common predictors (dividend-price ratio; earnings-price ratio; short interest rate; and term spread), using monthly data over the period 1950-1987. Based on a pooled estimation method which provides estimation and testing outcomes corrected for the Stambaugh bias, Hjarmarsson (2010) finds that the dividend-price and earnings-price ratios show a limited predictability for stock return, but the interest rate variables are found to be robust predictors in developed markets. Jordan et al. (2014a) investigate return predictability for 14 European and Mediterranean countries, including developed and emerging markets, Euro and non-Euro currency countries, as well as small and medium-sized economies. They use monthly fundamental-price ratios, macroeconomic and technical variables, covering the period 1995-2011. They find some evidence that predictive ability of fundamentals is related to liquidity and market development, and technical variables provide larger economic gains in both larger and more developed markets. Their results suggest that the predictability can differ depending upon a country's size, liquidity and development.

Wohar et al. (2005) examine return predictability using monthly macroeconomic variables data in 12 industrialized countries, using the data from the earlyto-mid 1970s to the late 1990s. They find that interest rates are the most consistent and reliable predictors of stock returns across countries, while the inflation

\footnotetext{
${ }^{2}$ The beginning date is different according to the country.
} 
rate also appears to have important predictive ability in certain countries. Jordan et al. (2014b) analyze return predictability for 11 Asian countries over the period 1995-2011, using monthly data for three types of predictors (fundamental, macroeconomic and technical variables). They find that the performance of fundamentalprice ratios and macroeconomic variables as well as some technical variables shows evidence of predictability. Schrimpf (2010) examines return predictability in five major international stock markets, using a monthly data set of nine financial and macroeconomic predictors, covering the period 1973-2007. He finds, adopting the ARM of Amihud et al. (2009), that interest-rate related variables are usually among the most prominent predictive variables, whereas valuation ratios perform rather poorly. Further, he reports that the return predictability of international stock markets is not uniform across countries. Giot and Petitjean (2011) examine the predictability of stock returns in ten international markets using a linear predictive regression model applying the Stambaugh (1999) and Lewellen (2004) correction methods, using the data to 2005 and considering five traditional predictors. Their out-of-sample analysis shows that the short-term interest yield is the most informative predictor of stock returns.

Some studies focus on the UK stock market. McMillan (2003) considers nonlinear smooth-transition threshold models to analyze the predictability of UK stock market returns with a variety of financial and macroeconomic variables over the period 1975-1995. Their result shows that the exponential smooth transitions threshold model improves both the in-sample fit and out-of-sample forecast of the data over both the linear and logistic smooth transitions threshold alternatives, based on dividend yield, industrial production and short-term interest rate. Pesaran and Timmermann (2000) use a recursive modelling strategy to the UK stock market which allows to identify a number of genuine ex ante predictors of excess returns over the period 1965-1993. Their analysis suggests that the best forecasting models is likely to change considerably over time, using various business cycle variables. Overall, McMillan (2003) and Pesaran and Timmermann (2000) suggest that dividend yields may present out-of-sample predictive power in the UK context. This result is confirmed by Kellard et al. (2010) by evaluating the ability of dividend ratios (dividend-price ratio and dividend-yield) to predict the UK and US excess returns covering the period from 1975 to 2009. They find that both the dividendprice ratio and the dividend yield are significant in both markets from in-sample univariate regressions. However, the out-of-sample models indicate that dividend 
ratios are only useful predictors of UK excess returns. Further, Andriosopoulos et al. (2014) examine whether actual share repurchases via the total payout ratio variable can enhance the ability of the dividend-price ratio to predict the equity premium in the UK and French stock markets over the period 1990-2010. They show that the total payout ratio is a useful predictor of the UK and French equity premia. However, it fails to outperform the dividend-price ratio in both markets. This finding in the return predictability literature implies that the predictive performance of the total payout ratio may be driven by the information conveyed by the dividends rather than the actual share repurchase activity.

On the methodological side, Wohar et al. (2005) and Jordan et al. (2014a, 2014b) adopt the predictive model which treats a predictor variable exogenously. As a result, their estimation and testing outcomes may be subject to the Stambaugh bias. Schrimpf (2010) and Andriosopoulos et al. (2014) adopt the ARM method of Amihud et al. $(2009,2010)$, which is inferior to the improved ARM proposed by Kim (2014a) in small sample properties and implementations. We also note that the improved ARM to be used in this paper is more general than the Stambaugh (1999) and Lewellen (2004) correction procedures which Giot and Petitjean (2011) adopt. As mentioned earlier, all past studies use the model with lag order one. For monthly data, the predictive model of lag order one may be misspecified because monthly stock return or predictors may show a higher order dependence than one. As an alternative to the improved ARM, we also use the wild bootstrap procedure with resampling conducted based on EGLS estimation, which has not been adopted by the past studies on the stock return predictability of international markets.

\section{Data}

We consider monthly data from a large number of international markets from January 2000 to June 2014. Our sample includes 16 Asian-Pacific markets (Australia, China, Hong-Kong, India, Indonesia, Japan, South Korea, Malaysia, New Zealand, Pakistan, Philippines, Singapore, Sri Lanka, Taiwan, Thailand, and the United States); 16 European markets (Austria, Belgium, Cyprus, Denmark, Finland, France, Germany, Greece, Italy, The Netherlands, Norway, Portugal, Spain, Sweden, Switzerland, and the UK); and 5 Eastern European markets (Czech Republic, Hungary, Poland, Romania, and Russia). The data are obtained from 
Thomson Financial Datastream, using the Datastream Total Market Index. The composition of these stock markets represents a well-diversified mixture of developed, emerging, and under-developed markets. According to the Morgan Stanley Capital International (MSCI) classifications ${ }^{3}$, there are three different groups of markets:

- Developed markets: Australia, Austria, Belgium, Denmark, Finland, France, Germany, Greece, Hong-Kong, Italy, Japan, The Netherland, New Zealand, Norway, Portugal, Spain, Sweden, Switzerland, the UK, the United States;

- Emerging markets: China, Czech Republic, Hungary, India, Indonesia, Poland, South Korea, Malaysia, Philippines, Russia, Taiwan, Thailand;

- Frontier markets: Cyprus, Pakistan, Romania, and Sri Lanka.

Stock returns are calculated as the log difference in the stock return index (RI): $Y_{t}=\log \left(R I_{t} / R I_{t-1}\right)$, where $\log$ is the natural logarithm. Following Jordan et al. (2014), we include four financial ratios and two technical variables as well as one macroeconomic variable:

- Dividend-price ratio (log), (DP): difference between the log of dividends paid on the market index and the log of stock prices, where dividends are measured using a one-year moving sum;

- Dividend-yield (log), (DY): difference between the log of dividends and the $\log$ of 1 month lagged stock prices;

- Earnings-price ratio (log), (EP): difference between the log of earnings on the market index and the log of stock prices, where earnings are measured using a one-year moving sum;

- Dividend-payout ratio (log), (DE): difference between the log of dividends and the log of earnings;

\footnotetext{
${ }^{3}$ The MSCI Market Classification Framework consists of following three criteria: economic development, size and liquidity as well as market accessibility. Standard \& Poor's Dow Jones also proposes three major country classifications - developed, emerging, and frontier. To be eligible for inclusion in the S\&P Global Equity Series Index, a country should satisfy minimum requirements for market capitalization, annual turnover and the market development ratio defined as the ratio of full domestic market capitalization to the country's nominal GDP, a measure of market depth. Additional criteria with regard to the securities settlement period, Sovereign debt rating, hyperinflation, foreign ownership restrictions and accessibility of foreign currency are also considered. The MSCI and S\&P Dow Jones classifications are similar, except for South Korea and Taiwan considered as Developed market.
} 
- Short-term interest rate, (STIR): the 3-month Treasury bill rate ${ }^{4}$;

- Price pressure, (PRES): $\log$ of the ratio of the number of rising stocks in the previous month divided by the number of falling stocks;

- Change in volume, $(\mathrm{CVm})$ : the monthly change in the volume of traded stocks (in the index).

Technical indicators rely on past price and volume patterns to identify price trends believed to persist into the future. According to Neely et al. (2014), there are basically four types of theoretical models that explain why technical indicators can have predictive ability, all of which point to an informationally inefficient market: (i) recognizing differences in the time for investors to receive information, (ii) assuming different responses to information by heterogeneous investors, (iii) allowing for underreaction and overreaction to information, and (iv) describing investor sentiment. Some studies find evidence supporting technical indicators having significant predictive power on the equity risk premium (e.g., Brock et al., 1992; Bessembinder and Chan, 1998; Lo et al., 2000; Han et al., 2013; Neely et al., 2014).

Following Jordan et al. (2014a, 2014b), we take two technical variables: the price pressure (PRES) and change in volume (CVm). PRES measures the extent of aggregate momentum in the market overall. It could also be interpreted as an indicator of sentiment of investors to stocks in a country. It is high when most stocks have a rise in price in a month and very few have a fall in the same month. $\mathrm{CVm}$ is an indicator of the direction where the volume trend moves. Volume is an important aspect of technical analysis because it can be used as an indicator for price trends. Momentum and volume-based indicators are representative of the trend-following technical indicators (e.g., Brock et al., 1992; Sullivan et al., 1999).

Tables 2-3 provide a summary of descriptive statistics (mean and standard deviation) for each independent variable used and for the aggregate market return. The average nominal returns vary substantially across countries from $-1.6 \%$ per month in Cyprus, up to $1.6 \%$ per month in Pakistan. Three European countries (Finland, Cyprus and Greece) display negative returns. The standard deviation

\footnotetext{
${ }^{4}$ Where Treasury bill rate data are not available, we take the money market rate (Denmark, Czech Republic, Finland, Poland, Romania, Russia, Indonesia, South Korea, Philippine, Singapore, and Thailand) or the 3-month interbank rate (Austria, Germany, Norway, The Netherlands, and Portugal). For Japan, we use the bank deposit rate. The stock markets with interest rate data not fully available or not showing sufficient fluctuations are excluded from the analysis.
} 
of returns also varies substantially across countries from 0.092 for Cyprus to 0.035 for Australia. We also report the estimated values of the first-order autoregressive parameter and the results of the ADF-GLS unit root test. As found by Cavanagh et al. (1995), Campbell and Yogo (2006), and Kostakis et al. (2015), among others, all the predictors (except for Cvm) exhibit the first-order autoregressive coefficient estimates fairly close to 1 , for most of the countries. This indicates that all predictors are highly persistent, except for CVm. The unit root test shows that the null hypothesis of unit root is not rejected at the $5 \%$ or $10 \%$ level for most of the predictors, consistent with our observations that the predictors are highly persistent.

\section{Methodology}

This section provides the details of parameter estimation and statistical inference for the predictive model of stock return. We present the improved ARM of Kim (2014a) and the wild bootstrap LR test (or equivalently system F-test) based on a (restricted) VAR form of predictive model.

\subsection{Predictive regression}

We consider a predictive model for stock return $Y$ as a function of a predictor $X$ with lag order $p$, which can be written as

$$
\begin{gathered}
Y_{t}=\delta_{0}+\beta_{1} X_{t-1}+\ldots+\beta_{p} X_{t-p}+u_{t} \\
X_{t}=\delta_{1}+\alpha_{1} X_{t-1}+\ldots+\alpha_{p} X_{t-p}+v_{t} .
\end{gathered}
$$

It is assumed that the error terms have fixed (unconditional) variances and covariances: $\operatorname{Var}\left(u_{t}\right) \equiv \sigma_{u}^{2}, \operatorname{Var}\left(v_{t}\right) \equiv \sigma_{v}^{2}$ and $\operatorname{Cov}\left(u_{t}, v_{t}\right) \equiv \sigma_{u v}$. We denote $\Sigma$ as the covariance matrix of $u_{t}$ and $v_{t}$. Under $H_{0}: \beta_{1}=\ldots=\beta_{p}=0$, the predictor $X$ has no predictive power for $Y$. We assume that the order $p$ is known for the purpose of exposition, but it will be treated as unknown in our empirical analysis.

The above model treats the predictors as endogenous, but the least-squares (LS) estimators for $\left(\beta_{1}, \ldots, \beta_{p}\right)$ are still biased as long as $\sigma_{u v} \neq 0$. It is because the LS estimators completely ignore the presence of $\sigma_{u v}$ (see Stambaugh; 1999). As mentioned earlier, this estimation bias can substantially over-state the magnitudes 
of predictive coefficients and their statistical significance. This is particularly so when the predictor is persistent and the correlation among the error terms is high, which is widely encountered in practice: see, for example, Amihud et al. (2009, 2010). In this section, we present two alternative methods of bias-corrected estimation and statistical inference: one based on the asymptotic method (improved $\mathrm{ARM}$ ) and the other on a non-parametric method (wild bootstrap $L R$ or $F$ test).

\subsection{Improved Augmented Regression Method}

The improved ARM of Kim (2014a) is a modified version of the ARM proposed earlier by Amihud and Hurwich (2004) and Amihud et al. (2009, 2010). The method assumes that the error terms in (1) and (2) are linearly related as $u_{t}=$ $\phi v_{t}+e_{t}$ where $e_{t}$ is an independent normal error term with a fixed variance. It involves running the regression for $Y$ against $X$ 's given in (1), augmented with the bias-corrected residuals from the predictor equations (2). That is, we run the regression of the form

$$
Y_{t}=\delta_{0}+\beta_{1} X_{t-1}+\ldots+\beta_{p} Y_{t-p}+\phi \hat{v}_{t}^{c}+e_{t}
$$

where $\hat{v}_{t}^{c} \equiv X_{t}-\hat{\delta}_{1}^{c}-\hat{\alpha}_{1}^{c} X_{t-1}-\ldots-\hat{\alpha}_{p}^{c} X_{t-p}$, while $\hat{\delta}_{1}^{c}$ and $\hat{\alpha}_{i}^{c}$ 's are the bias-corrected estimators for $\delta_{1}$ and $\alpha_{i}$ 's. Amihud et al. (2010) adopt the asymptotic formulae derived by Shaman and Stine (1988) to obtain these bias-corrected estimators. The bias-corrected estimators $\left(\hat{\beta}_{1}^{c}, \ldots, \hat{\beta}_{p}^{c}\right)$ for $\left(\beta_{1}, \ldots, \beta_{p}\right)$ are obtained from the augmented regression (3). The $F$ test for $H_{0}$ is conducted using the covariance matrix for $\left(\hat{\beta}_{1}^{c}, \ldots, \hat{\beta}_{p}^{c}\right)$, whose details are given in Amihud et al. (2010). They provide Monte Carlo evidence that their ARM performs substantially better than the conventional LS method in parameter estimation and statistical inference.

Kim (2014a) proposes three modifications to the ARM of Amihud et al. (2010). The first is the bias-correction method of a higher order accuracy than the one used by Amihud et al. (2010). The second is the use of stationarity-correction (Kilian, 1998), which ensures that the bias-corrected estimators satisfy the condition of stationarity. This correction is important because bias-correction often makes the model (1) and (2) non-stationary (see Lewellen, 2004). The third is the use of matrix formula for bias-correction, which makes the implementation of the ARM for a higher order model computationally easier. According to the Monte Carlo study of Kim (2014a), the improved ARM provides more accurate parameter estimation 
and statistical inference than the ARM in small samples. In addition, since it makes use of a simple matrix formula for bias-correction, the improved ARM can easily be implemented for a higher order predictive model with $p>1$.

\subsection{Wild bootstrap test based on EGLS estimation}

The predictive model given in (1) to (2) can be viewed as a restricted VAR model (see Lutkepohl, 2005) or a dynamic SUR (seemingly unrelated regression) model of Zellner (1962). For these models, it is well-known that the conventional LS estimation is inefficient and that the estimated generalized least-squares (EGLS) estimators should be preferred in general. The EGLS estimator is identical to the LS only under special conditions: when contemporaneous correlations among the error terms are zero or when each equation share the same regressors. It is more efficient than the LS since it takes explicitly account of contemporaneous correlations among the error terms in estimation. Recently, Kim (2014b) provides Monte Carlo evidence that the EGLS estimator is practically unbiased in the context of predictive model such as (1) - (3), and that its efficiency gain is particularly high when the predictors are highly persistent and when the error terms are strongly correlated. This suggests that the EGLS estimation be preferred to the LS in testing for no return predictability.

To test for $H_{0}: \beta_{1}=\ldots=\beta_{p}=0$, we use the LR test of the form

$$
L R=T\left[\log \left(\mid \widetilde{\Sigma}\left(H_{0} \mid\right)-\log \left(\left|\widetilde{\Sigma}\left(H_{1}\right)\right|\right)\right]\right.
$$

where $\widetilde{\Sigma}\left(H_{i}\right)$ is the estimator for $\Sigma$ of the model (1)-(2) based on EGLS estimation under $H_{i}(i=0,1), T$ is the sample size, $|A|$ indicates the determinant of a matrix $A$, and $\log$ denotes the natural logarithm. The above $L R$ statistic asymptotically follows the chi-squared distribution with $p$ degrees of freedom, where $p$ is the number of restrictions under $H_{0}$. Equivalently, one may wish to use $F \equiv L R / p$ statistic, which asymptotically follows the $F$ distribution with $(p, T-K)$ degrees of freedom, where $K$ is the number of parameters under $H_{1}$ (Lutkepohl, 2005; p.141). In this paper, we use the $F$ test version of (4), to be consistent with the $F$-test associated with the (improved) ARM.

It is well-known that an asymptotic test shows poor small-sample performance for a dynamic model such as the VAR; and the bootstrap is suggested as an alternative for improved performance in many applications: see, for example, Kim 
(2014b) and Kilian (1999). In this paper, we also adopt the bootstrap to improve small sample performance of the $F$ test. The bootstrap involves generating an artificial data set $\left\{Y_{t}^{*}, X_{t}^{*}\right\}_{t=1}^{T}$ under $H_{0}$ as follows:

$$
\begin{array}{r}
Y_{t}^{*}=\tilde{\delta}_{0}+u_{t}^{*} \\
X_{t}^{*}=\tilde{\delta}_{1}+\tilde{\alpha}_{1} X_{t-1}^{*}+\ldots+\tilde{\alpha}_{p} X_{t-p}^{*}+v_{t}^{*}
\end{array}
$$

where $\tilde{\gamma} \equiv\left(\tilde{\delta}_{0}, \tilde{\delta}_{1}, 0, \ldots, 0, \tilde{\alpha}_{1}, \ldots, \tilde{\alpha}_{p}\right)$ are the EGLS estimators for

$$
\left(\delta_{0}, \delta_{1}, \beta_{1}, \ldots, \beta_{p}, \alpha_{1}, \ldots, \alpha_{p}\right)
$$

imposing the restrictions under $H_{0}$; and $\left(u_{t}^{*}, v_{t}^{*}\right)$ is the re-sampled residuals. The initial values of the above generation are the first $p$ values of $X$. The resampled residuals are obtained from the residuals associated $\tilde{\gamma}$ in the manner that the contemporaneous correlation between the error terms are effectively replicated. In this paper, we employ the wild bootstrap version (Mammen, 1993), which provides statistical inference robust under unknown forms of (conditional) heteroskedasticty. With the wild bootstrap, resampled residuals are obtained as $\left(u_{t}^{*}, v_{1 t}^{*}\right)=\left(\eta_{t} \tilde{u}_{t}, \eta_{t} \tilde{v}_{t}\right)$ where $\left(\tilde{u}_{t}, \tilde{v}_{t}\right)$ are the residuals associated with the EGLS estimators $\tilde{\gamma}$, and $\eta_{t}$ is an independent random variable with zero mean and unit variance. A popular form of $\eta_{t}$ is the two-point distribution of Mammen (1993), which is given by $\eta_{t}=(1+\sqrt{5}) / 2$ with probability $p=(\sqrt{5}-1) / 2 \sqrt{5}$ and $\eta_{t}=(1-\sqrt{5}) / 2$ with probability $1-p$. By resampling the residuals in this way, the (conditional) heteroskedasicity and contemporaneous correlations among the error terms can be effectively replicated: see, for more details, Hafner and Herwarz (2009) and Kim (2014b). As a result, the wild bootstrap provides statistical inference robust to (conditional) heteroskedasticity and contemporaneous correlations present in VAR error terms.

From the artificial data set $\left\{Y_{t}^{*}, X_{t}^{*}\right\}_{t=1}^{T}$, the $F=L R / p$ statistic is calculated, which is denoted as $F^{*}$. The above resampling procedure (5) to (6) is repeated sufficiently many times, say $B$, to generate the bootstrap distribution of the $F$ statistic $\left\{F^{*}(i)\right\}_{i=1}^{B}$. This distribution is used as an approximation to the unknown true sampling distribution of the $F$ statistic. It is often the case that the bootstrap distribution provides more accurate approximation to the sampling distribution than an asymptotic distribution (see, MacKinnon; 2002). The bootstrap $p$-value can be calculated as the proportion of the members of $\left\{F^{*}(i)\right\}_{i=1}^{B}$ greater than the 
observed $F$ statistic. If the $p$-value is greater than the chosen level of significance $\alpha$, the null hypothesis of no predictability is rejected at $\alpha$ level of significance. The number of bootstrap iterations $B$ is set to 1000 for all bootstrap implementations.

\subsection{Further methodological details}

The two alternative methods presented above correct for the Stambaugh bias, by taking explicit account of contemporaneous correlations among the error terms, but their treatments of contemporaneous correlation error terms are different. The (improved) ARM assumes that the error terms are linearly related as $u_{t}=\phi v_{t}+e_{t}$, and incorporates this relationship into model estimation by augmenting the predictive regression. In contrast, the EGLS estimation conducts weighted least-squares estimation of the model (1) and (2), with the weights determined by the members of the covariance matrix of error terms $\Sigma$. Note that the improved ARM is operational under the assumption of normality, which can be highly restrictive in practice. The advantage of the wild bootstrap method is that it provides robust statistical inference under non-normality and (conditional) heteroskedasticity, which are well-known characteristics of stock return (see, e.g., Hansen and Lunde, 2005).

Kim (2014a) provides Monte Carlo evidence that the improved ARM shows the size (probability of rejecting the true null hypothesis) properties much better than the ARM of Amihud et al. (2009, 2010). This means that, with the former, the chance of spuriously rejecting the true null hypothesis of no return predictability is much smaller. Kim (2014a) also shows that the power (the probability of rejecting the false null hypothesis) of the improved ARM is higher than the ARM. In a recent study, Kim and Shamsuddin (2014) conduct Monte Carlo study that compares the size and power properties of the improved ARM and the wild bootstrap test described above. They report that the wild bootstrap test shows slightly superior size and power properties.

We note that the use of the bootstrap method in the context of predictive regression has not been extensive, although there have been a few studies that employed the bootstrap. Mark (1995) used the bootstrap with LS estimation which is subject to the Stambaugh bias; and Kilian (1999) employed the bootstrap based on the EGLS in the context of restricted vector error correction model with a parameter constraint, which was also adopted by Giot and Petitjean (2011). Huang 
et al. (2014) and Rapach et al. (2013) adopt a wild bootstrap procedure based on LS with bias-correction conducted using the asymptotic formulae similar to those of Shaman and Stine (1988). Note that our wild bootstrap is based on EGLS estimation and does not require bias-correction for improved small sample properties.

\section{Empirical Results}

In evaluating the return predictability of a range of predictors, we consider statistical significance of the predictive coefficients, their effect size estimates, and their out-of-sample forecasting performance for stock return. We estimate a predictive model with general lag order $p$ given in (1) and (2) for all markets. The unknown AR order $p$ is estimated using the Schwarz information criterion setting the maximum lag order 12 .

\subsection{Statistical significance and effect size}

We report the p-values for the test of $H_{0}: \beta_{1}=\ldots=\beta_{p}=0$, associated with the improved ARM as well as with the wild bootstrap F test. We also calculate the value of $\beta \equiv \beta_{1}+\ldots+\beta_{p}$, called the effect size of return predictability, which measures the total dynamic effect of the predictor $X$ on stock return. Note that $\beta$ is expressed in the form of elasticity for all cases: i.e., the change of log stock return (in percentage) with respect to 1 percent change of $X$. We report the improved ARM estimator for $\beta, \hat{\beta}^{c}=\hat{\beta}_{1}^{c}+\ldots+\hat{\beta}_{p}^{c}$, and its 95 percent confidence interval based on the improved ARM covariance matrix estimator for $\left(\hat{\beta}_{1}^{c}, \ldots, \hat{\beta}_{p}^{c}\right)$ given in Kim (2014a). If the confidence interval covers zero, we cannot reject the null hypothesis that the effect size value $\beta$ is 0 at the 5 percent level of significance. In each table for the respective predictors, we report the estimated order $p$; the p-values based on improved ARM and wild bootstrap; and the effect size estimates with 95 percent confidence interval.

Table 4 reports the case of DP as a predictor. For the Asia-Pacific stock markets, the F-test for no return predictability is rejected at a conventional level of significance, except for New Zealand and Sri Lankan markets. The effect size is found to be statistically no different from 0 , at 5 percent level, in eight markets; but the effect size estimates do not indicate strong effects. The median of the effect 
size is estimate is 0.02 , indicative of 0.02 percentage increase of stock return to a 1 percent increase of DP on average. The maximum of these values is 0.06 , which is the value for the Pakistan market. Most of the European markets show return predictability according to the F-test (except for Greece, Russia, Spain, and UK), ${ }^{5}$ but their effect size estimates are small and statistically no different from 0 for all cases. The similar feature is evident for the U.S. market, where the effect size is fairly small with no statistical significance at the 5 percent level.

Table 5 displays the results for DY as a predictor. Most of the markets show the evidence of return predictability at a conventional level of significance, according to the F-test (based on either asymptotic or bootstrap p-value): the only exception is the Philippine market. However, the effect size is again negligible and statistically insignificant. Only three markets show the evidence of statistically significance effect size (China, Hong Kong, and India). However, their point estimates are no more than 0.06 .

Table 6 reports the case of DE as a predictor. The evidence of return predictability is much stronger in this case than DP and DY. A number of stock markets show rejection of F-test for no return predictability, along with statistically significant effect size estimates: they include Indian, Indonesian, Malaysian, Philippine, Singapore, Thai, Belgian, Finland, France, Cyprus, Italy, Norway, Poland, and Spanish markets. The effect size estimates are also slightly higher, with the maximum of 0.1462 for the Indian market. The U.S. market shows no evidence of return predictability from DE.

The results for EP are given in Table 7. According to the F-test, most of the markets show evidence of return predictability with at least one of the asymptotic and bootstrap p-values indicate statistical significance at a conventional level of significance. However, most of effect size estimates are statistically no different from 0; even if they are, the effect size estimates are not large. For example, both U.S. and UK stock markets show return predictability at 10 percent level of significance, but the effect size estimates are negligible and statistically insignificant.

Table 8 reports the case of PRES. In this case, all markets show strong evidence of return predictability. Both asymptotic and bootstrap p-values of the F test are less than 0.01 for all markets. The effect size estimates are also statistically different

\footnotetext{
${ }^{5}$ This result on the UK is opposed to that obtained by Pesaran and Timmermann (2000), McMillan (2003), Kellard et al. (2010), and Andriosopoulos et al. (2014) who provide some evidence of return predictability by means of DP in the UK.
} 
from 0 at the 5 percent level, for all markets except for the Italian market. The median value of effect sizes are 0.1244 for the Asia-Pacific markets and 0.1288 for the European markets. For the U.S. market, the effect size value is 0.1006. This indicates that a 1 percent increase of PRES on average leads to more than 0.1 percent increase of stock return, which represents much higher values of effect size than those associated with the other predictors. Table 9 presents the results for Cvm. The evidence of statistically significant return predictability and positive effect size occurs only in Chinese, Indonesian, and Portuguese markets: but these markets show fairly small effect size estimates.

Table 10 presents the results for the interest rates as the predictor. For the AsiaPacific stock markets, statistically significance in-sample predictability is discovered only in Korean and Malaysian markets. The effect size is large and negative, where a 1 percent increase of interest rate is expected to lower the stock return by 1.24 percent and 1.60 percent, respectively for Korean and Malaysian markets. The evidence is much stronger for the European markets where the interest rate is found to be a statistically significant predictor in 15 out of 20 stock markets, with the median of the effect size estimates being -0.84 percent.

\subsection{Out-of-sample forecasting performance}

To compare the out-of-sample forecast performance of alternative predictors, we generate one-step ahead forecasts from recursive estimation of the predictive model given in (1) and (2). We start with the sample from January 2000 to June 2012; estimate the model using the improved ARM and EGLS methods; and generate 1-step ahead forecast for stock return in July 2012. And then we take the sample from January 2000 to July 2012 to estimate the model; and generate 1-step ahead forecast for stock return in August 2012. This process continues to the end of the data set, until we have a set of 24 1-step ahead forecasts from July 2012 to June 2014. We use Theil's $U$ to evaluate the forecast accuracy, which can be written as

$$
U=\frac{\sqrt{\sum\left(A_{t}-F_{t}\right)^{2}}}{\sqrt{\sum A_{t}^{2}}+\sqrt{\sum F_{t}^{2}}}
$$

where $A_{t}$ is the observed value of stock return at time $t(=1, \ldots, 24)$, and $F_{t}$ is the forecasts for the stock return. Note that, $U=0$ in the event of perfect forecasts, where $A_{t}=F_{t}$ for all $t$; while $U=1$ in the event of naive forecasts where $F_{t}=0$ 
for all $t$. As Jordan et al. (2014a; p.80) point out, Theil's $U$ is closely related with the out-of-sample $R^{2}$ used in the previous studies: out-of-sample $R^{2}=1-U^{2}$.

Table 11 presents Theil's $U$ values for all stock markets, obtained from the improved ARM and EGLS estimation methods. We report the median values of $U$ for 15 Asia-Pacific markets, excluding the U.S.; and the median values of 21 European markets. The $U$ values of the U.S. market are reported separately. The price pressure is the best performer in out-of-sample forecasting for the Asia-Pacific markets and for the U.S. market, followed by the interest rate which also provides fairly low $U$ values. The interest rate is the best performer for the European markets with the $U$ values lower than 0.6 , followed by the price pressure. It is evident from Table 11 that PRES and STIR provides the smallest $U$ values for all three categories, indicative of the forecasts for stock return with the highest accuracy, regardless of the estimation methods employed. Their $U$ values are well below 0.7 , which are associated with the values of out-of-sample $R^{2}$ higher than 0.5 approximately.

We also apply the model confidence set (MCS) procedure proposed by Hansen et al. (2011) to determine the set, $\mathcal{M}^{*}$, that consists of a subset of equivalent models in terms of superior predictive ability (Hansen and Lunde, 2005) which are superior to the other competing models from a collection of models, $\mathcal{M}_{0}$. The MCS procedure yields a model confidence set, $\widehat{\mathcal{M}}^{*}$, that is a set of models constructed to contain the best models with a given level of confidence. This MCS allows to get several models displaying equivalent forecasting performance and therefore gives robustness to the forecasting exercise rather than to base the forecasting analysis only on one model. The $t$-statistic is defined as

$$
T_{\max \mathcal{M}}=\max _{i \in \mathcal{M}} t_{i} \quad \text { with } t_{i}=\frac{\bar{d}_{i}}{\sqrt{\widehat{\operatorname{var}}\left(\bar{d}_{i}\right)}}
$$

where $\widehat{\operatorname{var}}\left(\bar{d}_{i}\right)$ denotes the estimate of $\operatorname{var}\left(\bar{d}_{i}\right), \bar{d}_{i}=m^{-1} \sum_{j \in \mathcal{M}} \bar{d}_{i j}$, and $\bar{d}_{i j}=$ $n^{-1} \sum_{t=1}^{n} d_{i j, t}$, with $d_{i j, t}=L_{i, t}-L_{j, t}$ for all $i, j \in \mathcal{M}_{0}$, and $L_{i, t}$ is a loss function. ${ }^{6}$ The $t$-statistic is associated with the null hypothesis of equal predictive ability (EPA) $H_{0, \mathcal{M}}: E\left(\bar{d}_{i}\right)=0$ for all $i \in \mathcal{M}$, where $\mathcal{M} \subset \mathcal{M}_{0}$. The MCS procedure consists on a sequential testing procedure, which eliminates at each step the worst model from $\mathcal{M}$, until the null hypothesis of EPA is accepted for all the models. If

\footnotetext{
${ }^{6} \bar{d}_{i j}$ measures the relative sample loss between the $i$-th and $j$-th models, while $\bar{d}_{i}$ is the sample loss of the $i$-th model relative to the average across models $\mathcal{M}$.
} 
the null of EPA is rejected for $\mathcal{M}=\mathcal{M}_{0}$, the worst performing model is excluded from the set $\mathcal{M} .^{7}$ By iterating, the procedure stops when the null hypothesis of EPA of the models still included in the set cannot be rejected. If $H_{0, \mathcal{M}}$ is accepted at level $\alpha$ then the MCS is the set $\widehat{\mathcal{M}}_{1-\alpha}^{*}$. We set the confidence level for the MCS to $\alpha=0.10,0.20$ and $0.50 .^{8}$

Tables 12 and 13 report the $p$-values of the MCS test, obtained from the improved ARM and EGLS approaches, respectively. STIR is the best predictor, with a p-value $=1.00$, in $43 \%$ of countries, especially for (developed) European stock markets in more than $50 \%$, and this predictor is also in $\widehat{\mathcal{M}}_{50 \%}^{*}$ for $70 \%$ of stock markets. The second best predictor is PRES for $32 \%$ of the countries, particularly for Asia-Pacific in more than 50\%, and it is included in $\widehat{\mathcal{M}}_{50 \%}^{*}$ for $62 \%$ of the stock markets ( $87 \%$ for Asia-Pacific stock markets). The results are very similar between both estimation methods. Note that DE is the best predictor for four countries. From the MCS test, we find that STIR and PRES are the two best predictors for stock return, which is consistent with our findings based on Theil's U. This finding may have some implications to a real time investor who wishes to allocate her assets between risky and risk-free assets. Although the question as to whether the outcomes of the MCS test can help a real time investor develop a profitable trading strategy is an interesting one, we leave the investigation along this line for possible future research, since the issue is beyond the scope of the current paper.

According to Rapach and Wohar (2006), predictive models for stock returns can be affected by structural instability. Since our data covers the period of the global financial crisis occurred in 2008, it is important to check if our results are robust under the sub-samples which do not include this period. For this purpose, we split the same into two parts: before 2008 and after 2009 excluding the observation in 2008 and 2009. We find that the main findings of the paper do not change under these sub-samples. Table 14 reports the median values of the effect size and their $95 \%$ confidence intervals obtained from the Asia-Pacific and European stock markets. Again, when the predictor is PRES, the effect size from the predictive model is large and positive; and the confidence intervals do not cover 0 , on average. This is evident for all stock markets including the U.S., both before and after the financial crisis. When the STIR is the predictor, the strong and negative effect size

\footnotetext{
${ }^{7}$ The choice of the worst model to be eliminated uses the following elimination rule: $e_{\max } \mathcal{M}=$ $\arg \max _{i \in \mathcal{M}} t_{i}$.

${ }^{8}$ The MCS $p$-values are computed using bootstrap implementation (Hansen et al., 2011).
} 
is observed for the European stock markets for both sub-samples, consistent with the whole sample results, while the median values of the $95 \%$ confidence intervals do not cover 0 only before the crisis.

\section{Concluding Remarks}

This paper evaluates the predictive ability of financial ratios, technical indicators and short-term interest rates for stock return of international markets. We use the up-to-date data for a large number of markets around the world (16 Asia-Pacific including U.S.; and 21 European markets). The financial ratios considered include the dividend-price ratio, dividend-yield, earnings-price ratio, dividend-payout ratio; and the technical indicators include the prices pressure (measuring the degree of price momentum) and change in volume. We take a general form of the predictive model in which a lag order higher than one is specified based on a fully datadependent method.

We adopt the improved augmented regression method of Kim (2014a), which is a modified version of the original method proposed by Amihud et al. (2009, 2010). As an alternative, we also use the wild bootstrap test based on estimated GLS estimation for a predictive model expressed as a restricted VAR form. While the former is an asymptotic method based on normal approximation, the latter is based on a non-parametric method of statistical inference robust to non-normality and (conditional) heteroskedasticity. Both methods take explicit account of the endogeneity of predictors for stock return, and provide bias-reduced estimation and statistical inference with substantially improved small sample properties (see Kim and Shamsuddin; 2014).

Using monthly data from January 2000 to June 2014, we have found that the financial ratios exhibit weak predictive ability for stock returns. They are often found to be statistically significant predictors (in-sample), but their effect sizes are fairly small and their out-of-sample forecasts perform poorly for nearly all cases. In contrast, the price pressure appears to be a strong predictor for stock return for nearly all stock markets, with statistically significance in-sample predictability, large effect size estimates, and accurate out-of-sample forecasts. In addition, the interest rate is also found to be a strong predictor for stock return with accurate out-of-sample forecasting performance, especially for the European markets. These 
findings provide strong evidence that, for a wide range of international stock markets, a momentum indicator (price pressure) and interest rate show a substantially higher degree of predictive ability for stock return than the financial ratios.

However, our study have some limitations. First, some studies showed that portfolio allocations can be improved by using predictive regressions (e.g., Almadi et al., 2014; Jordan et al., 2014). Therefore, it would be also interesting to examine whether the use of MCS could be closely associated with economic value, and could help investors to time-vary their portfolio allocations in trading strategies. Second, our approach does not take into account the availability of the predictors to use them in real-time forecasting, which can have an effect on the lags of the predictors, since the monthly macroeconomic variables are released (at least) one month later the financial variables. These issues are left for further research. 


\section{References}

[1] Ahn, D-H., Conrad, J., Dittmar, R.F., 2003. Risk adjustment and trading strategies. The Review of Financial Studies, 16, 459-485.

[2] Almadi, H., Rapach, D.E. and Suri, A. (2014). Return predictability and dynamic asset allocation: How often should investors rebalance? Journal of Portfolio Management, 40, 16-27.

[3] Amihud, Y., Hurvich, C.M., 2004. Predictive regression: a reduced-bias estimation method. Journal of Financial and Quantitative Analysis, 39, 813-841.

[4] Amihud, Y., Hurvich, C.M., Wang, Y., 2009. Multiple-predictor regressions: Hypothesis testing. Review of Financial Studies, 22, 413-434.

[5] Amihud, Y., Hurvich, C.M., Wang, Y., 2010. Predictive regression with orderp autoregressive predictors. Journal of Empirical Finance, 17, 513-525.

[6] Ang, A., Bekaert, G., 2007. Stock return predictability: Is it there? Review of Financial Studies, 20, 651-707.

[7] Andriosopoulos, D., Chronopoulos, D.K., Papadimitriou, F.I., 2014. Can the information content of share repurchases improve the accuracy of equity premium predictions? Journal of Empirical Finance, 26, 96-111.

[8] Bessembinder, H., Chan, K., 1998. Market efficiency and the returns to technical analysis. Financial Management, 27, 5-17.

[9] Blume, L., Easley, D., O'Hara, M., 1994. Market statistics and technical analysis: The role of volume. The Journal of Finance, 49, 153-181.

[10] Bossaerts, P., Hillion, P., 1999. Implementing statistical criteria to select return forecasting models: What do we learn? Review of Financial Studies, 12, 405-428.

[11] Brock, W., Lakonishok, J., LeBaron, B., 1992. Simple technical trading rules and the stochastic properties of stock returns. The Journal of Finance, 47, 1731-1764.

[12] Campbell, J.Y., Yogo, M., 2006. Efficient tests of stock return predictability. Journal of Financial Economics, 81, 27-60.

[13] Cavanagh, C.L., Elliott, G., Stock., J.H., 1995. Inference in models with nearly integrated regressors. Econometric Theory, 11, 1131-1147. 
[14] Cochrane, J.H., 2008. The dog that did not bark: A defence of return predictability. Review of Financial Studies, 21, 1533-1575.

[15] Conrad, J., Kaul, G., 1998. An anatomy of trading strategies. The Review of Financial Studies, 11, 489-519.

[16] Diebold, F.X., Mariano, R.S., 1995. Comparing predictive accuracy. Journal of Business and Economic Statistics, 13, 253-263.

[17] Genay, R., Stengos, T., 1998. Moving average rules, volume and the predictability of security returns with feedforward networks. Journal of Forecasting, 17, 401-414.

[18] Giot, P., Petitjean, M., 2011. On the statistical and economic performance of stock return predictive regression models: An international perspective. Quantitative Finance, 11, 175-193.

[19] Goyal, A., Welch, I., 2003. Predicting the equity premium with dividend ratios. Management Science, 49, 639-654.

[20] Hafner, C.M. and Herwarz, H. 2009. Testing for linear vector autoregressive dynamics under multivariate generalized autoregressive heteroskedasticity. Statistica Neerlandica, 63, 294-323.

[21] Han, Y., Yang, K., Zhou, G., 2013. A new anomaly: The cross-sectional profitability of technical analysis. Journal of Financial and Quantitative Analysis, 48, 1433-1461.

[22] Hansen, P.R., Lunde, A., 2005. A forecast comparison of volatility models: does anything beat a $\operatorname{GARCH}(1,1)$ ? Journal of Applied Econometrics, 20, 873-889.

[23] Hansen, P.R., Lunde, A., Nason, J.M., 2011. Model confidence sets for forecasting models. Econometrica, 79, 453-497.

[24] Hjalmarsson, E., 2010. Predicting global stock returns. Journal of Financial and Quantitative Analysis, 45, 49-80.

[25] Huang, D., Jaing F.,Tu, J., Zhou, X., 2014. Investor sentiment aligned: A powerful predictor of stock returns. The Review of Financial Studies, forthcoming.

[26] Jegadeesh, N., Titman, S., 2001. Profitability of momentum strategies: An evaluation of alternative explanations. The Journal of Finance, 56, 699-720. 
[27] Jordan, S.J., Vivian, A.J., Wohar, M.E., 2014a. Forecasting returns: New European evidence. Journal of Empirical Finance, 26, 76-95.

[28] Jordan, S.J., Vivian, A.J., Wohar, M.E., 2014b. Forecasting Asian market returns: Bagging or combining? Working Paper.

[29] Kellard, N.M., Nankervis, J.C., Papadimitriou, F.I., 2010. Predicting the equity premium with dividend ratios: Reconciling the evidence. Journal of Empirical Finance, 17, 539-551.

[30] Kim, J.H., 2014a, Predictive regression: An improved augmented regression method. Journal of Empirical Finance, 26, 13-25.

[31] Kim, J. H., 2014b, Testing for parameter restrictions in a stationary VAR model: A bootstrap alternative. Economic Modelling, 41, 267-273.

[32] Kim. J. H., 2014c, VAR.etp: VAR modelling: estimation, testing, and prediction. $\mathrm{R}$ package version 0.61. URL: http://cran.rproject.org/web/packages/VAR.etp/index.html

[33] Kim, J. H., Shamsuddin, Abul, 2014, A Bootstrap Inference for Predictive Regression: Can Dividend Yield Predict Stock Return? Available at SSRN: http://ssrn.com/abstract $=2532122$

[34] Kilian, L. 1999. Exchange rates and monetary fundamentals: What do we learn from long-horizon regressions? Journal of Applied Econometrics, 14, 491-510.

[35] Kostakis, A., Magdalinos, T., Stamatogiannis, M.P., 2015. Robust econometric inference for stock return predictability. Review of Financial Studies, 28, 15061553.

[36] Lettau, M., S. Van Nieuwerburgh, 2008. Reconciling the return predictability evidence. The Review of Financial Studies, 21 (4), 1607-1652.

[37] Lewellen, J., 2004. Predicting returns with financial ratios. Journal of Financial Economics, 74, 209-235.

[38] Lo, A.W., Mamaysky, H., Wang, J., 2000. Foundations of technical analysis: Computational algorithms, statistical inference, and empirical implementation. The Journal of Finance, 55, 1705-1765.

[39] Lutkepohl, H. 2005, New Introduction to Multiple Time Series Analysis. Springer. 
[40] MacKinnon, J. G., 2002. Bootstrap inference in econometrics. Canadian Journal of Economics, 35, 615-645.

[41] Mammen, E., 1993. Bootstrap and wild bootstrap for high dimensional linear models. The Annals of Statistics, 21, 255-285.

[42] Mark, N.C., 1995. Exchange rates and fundamentals: Evidence on longhorizon predictability. American Economic Review, 85, 201-218.

[43] McMillan, D.G., 2003. Non-linear predictability of UK stock market returns. Ooford Bulletin of Economics and Statistics, 65, 557-573.

[44] Neely, C.J., Rapach, D.E., Tu, J., Zhou, G., 2014. Forecasting the equity risk premium: The role of technical indicators. Management Science, 60, 17721791.

[45] Pesaran, M.H., Timmermann, A., 2000. A recursive modelling approach to predicting UK stock returns. Economic Journal, 110, 159-191.

[46] Rapach, D., J. Strauss, and G. Zhou, 2013, International stock return predictability: what is the role of the United States? Journal of Finance 68, 1633-1662.

[47] Rapach, D., Wohar, M. 2006, Structural Breaks and Predictive Regression Models of Aggregate U.S. Stock Returns, Journal of Financial Econometrics, $4(2), 238-274$.

[48] R Core Team (2014). R: A language and environment for statistical computing. R Foundation for Statistical Computing, Vienna, Austria. URL http://www.R-project.org/.

[49] Schrimpf, A., 2010. International stock return predictability under model uncertainty. Journal of International Money and Finance, 29, 1256-1282.

[50] Shaman, P., Stine, R.A., 1988. The bias of autoregressive coefficient estimators. Journal of American Statistical Association, 83, 842-848.

[51] Stambaugh, R.F., 1999. Predictive regressions. Journal of Financial Economics, 54, 375-421.

[52] Sullivan, R., Timmermann, A., White, H., 1999. Data-snooping, technical trading rule performance, and the bootstrap. Journal of Finance, 54, 16471691. 
[53] Welch, I. Goyal, A. 2007, A Comprehensive look at the empirical performance of equity premium prediction. The Review of Financial Studies, 21 (4), 14551508.

[54] Wohar, M.E., Rapach, D.E., Rangvid, J., 2005. Macro variables and international stock return predictability. International Journal of Forecasting, 21, $137-166$.

[55] Zellner, A., 1962. An efficient method of estimating seemingly unrelated regression and tests of aggregation bias. Journal of the American Statistical Association, 57, 500-509. 


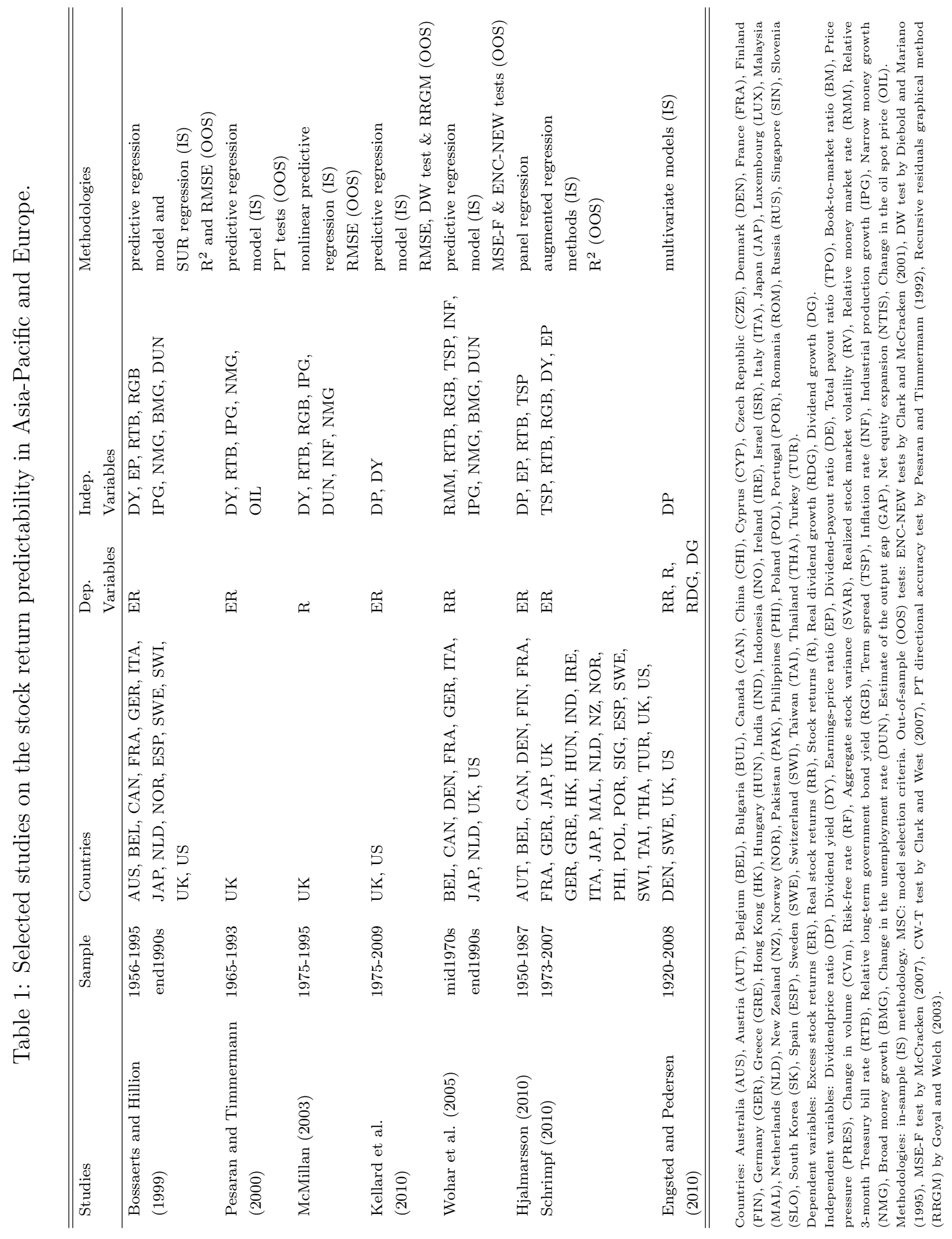




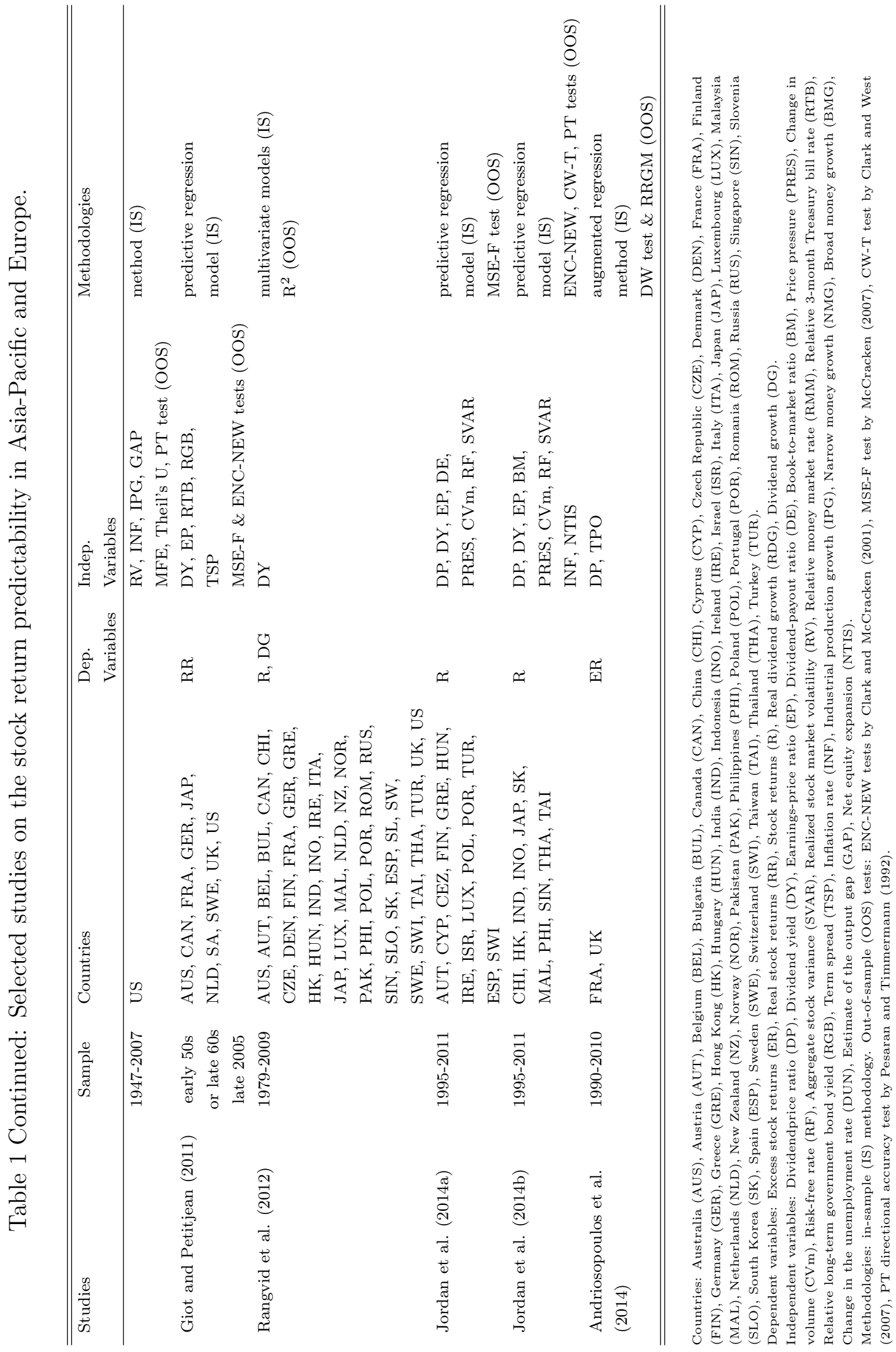




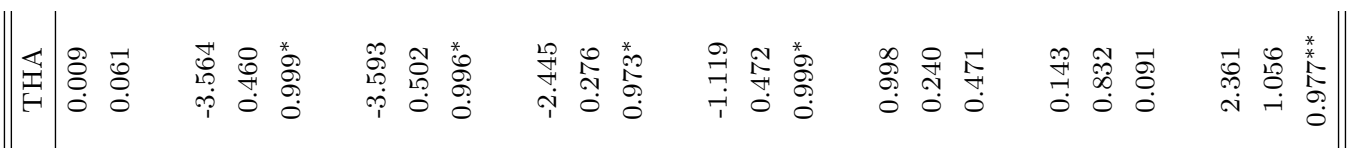

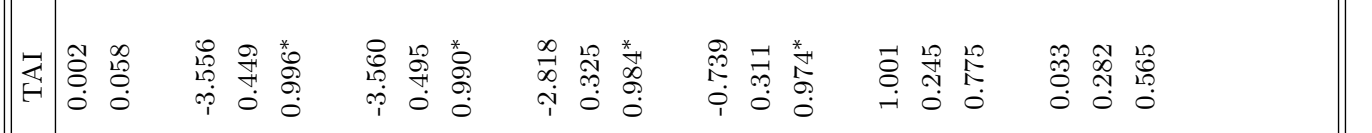

II

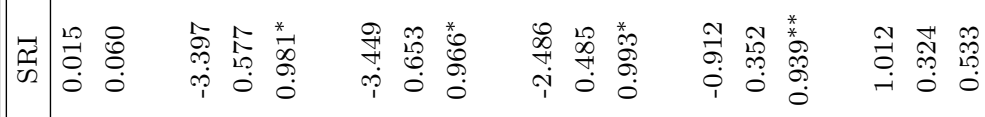

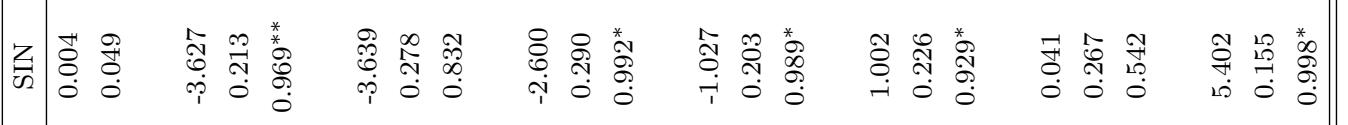

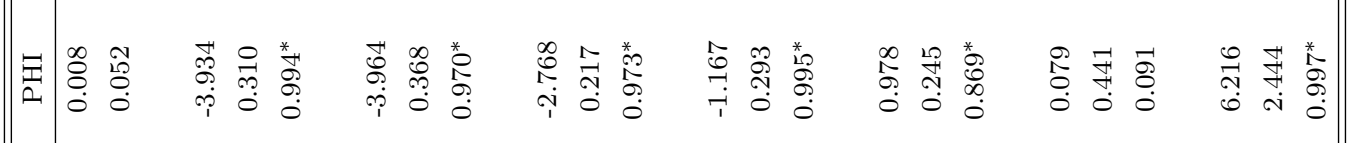

夏

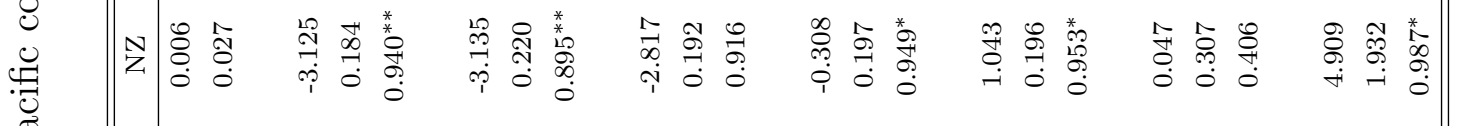

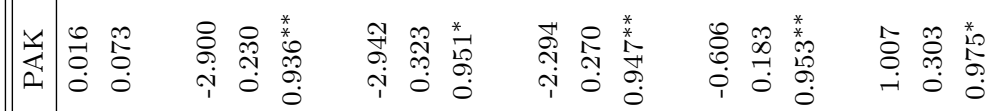

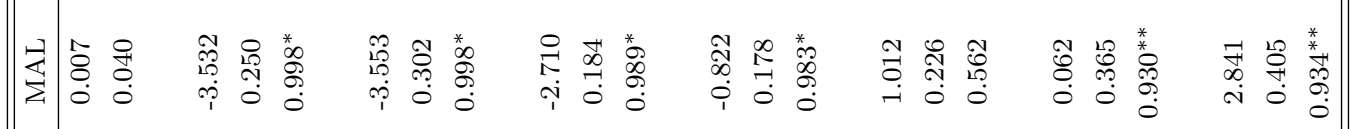

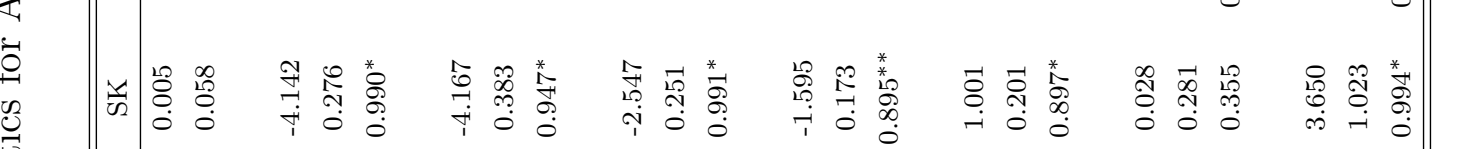

总

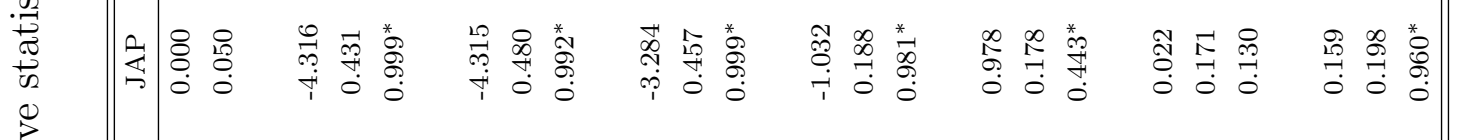

毫織

量旁

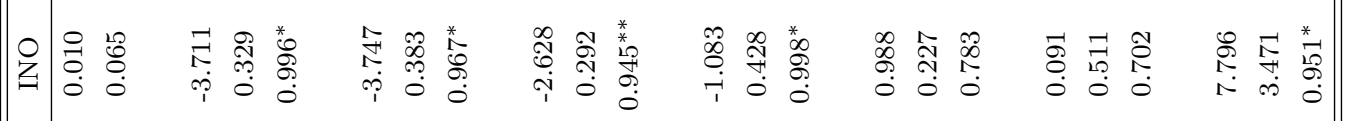

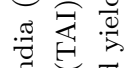

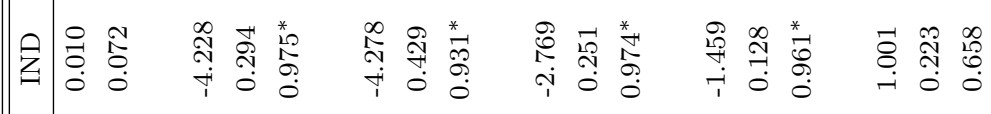

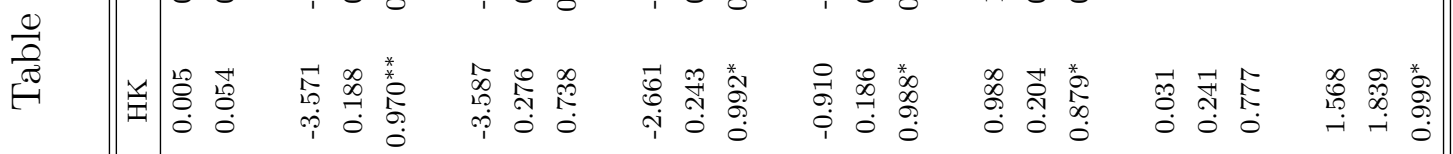

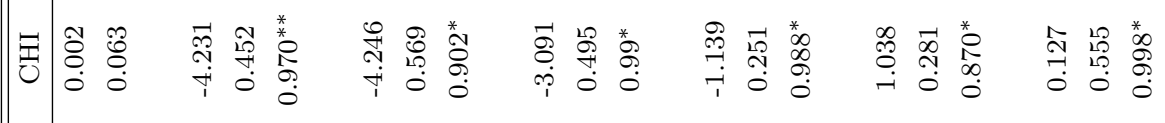

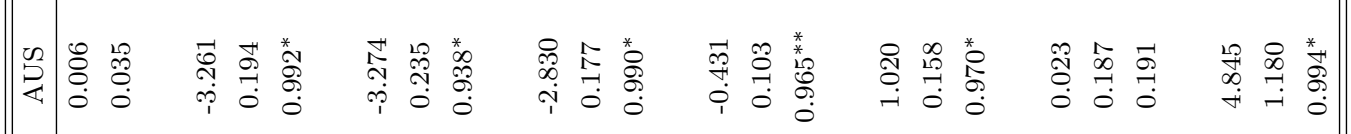

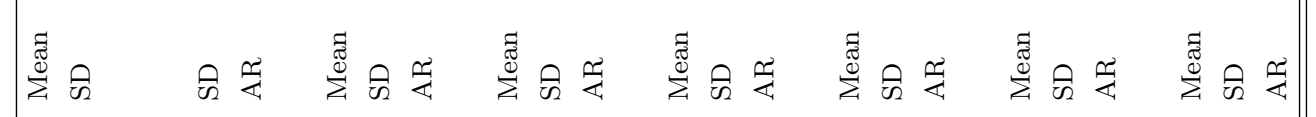

迸离离

䪪离会

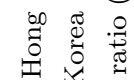

鸽旁

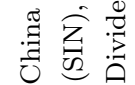

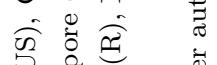

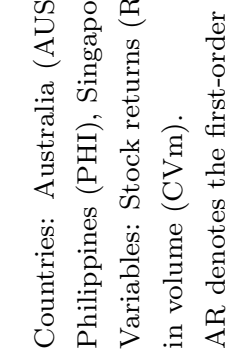




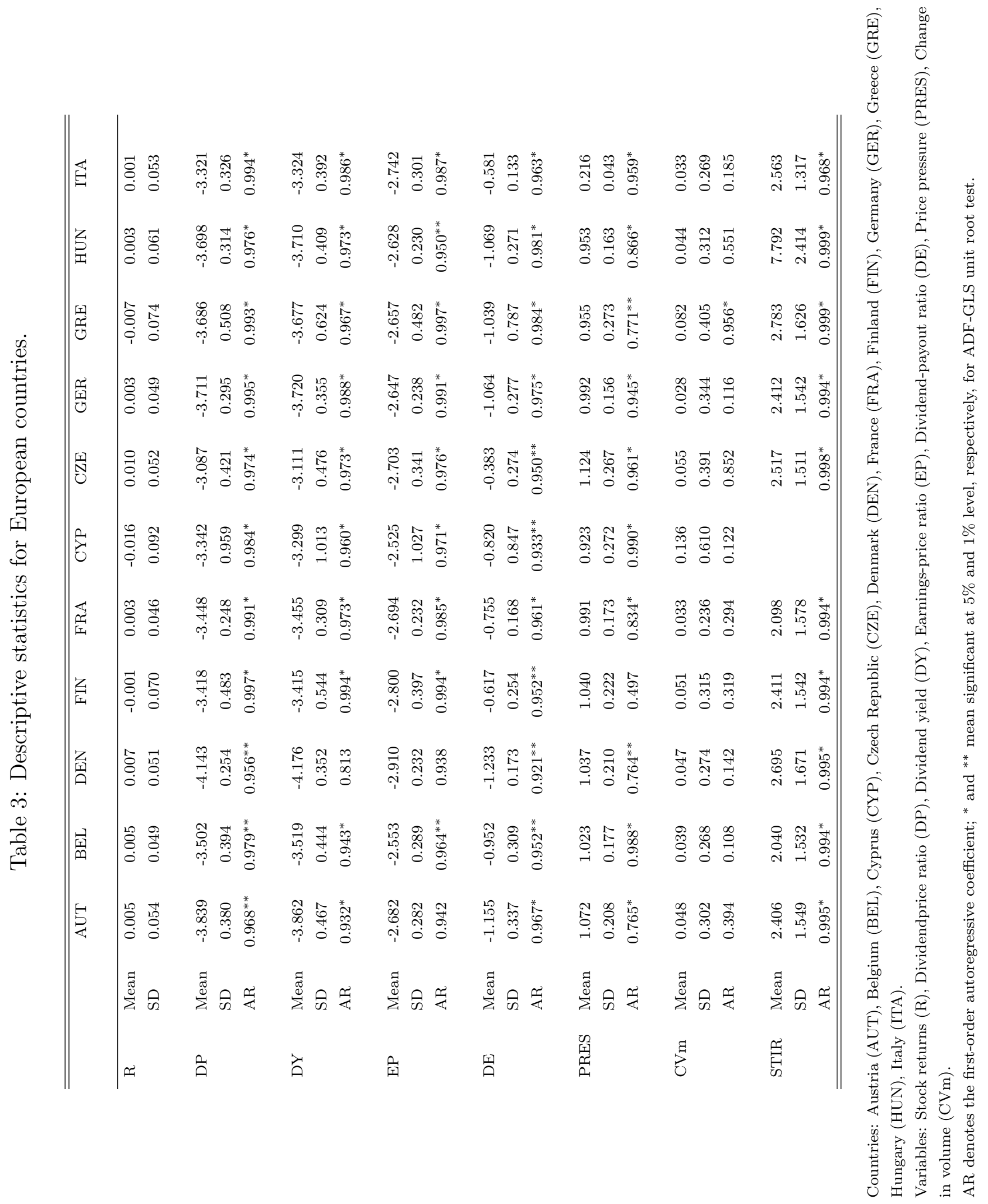




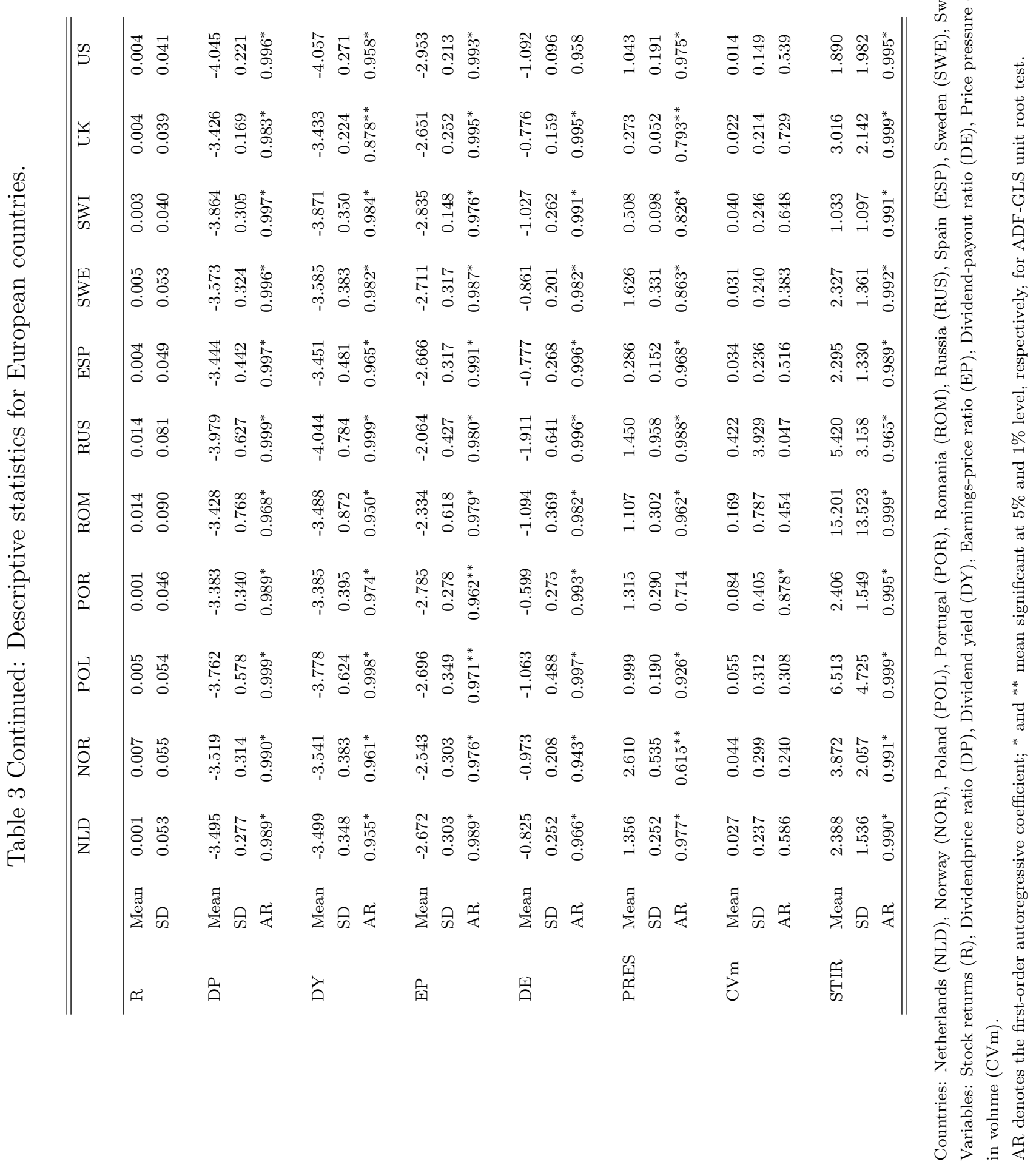


Table 4: Predictability of Asia-Pacific and European stock returns - DP predictor.

\begin{tabular}{|c|c|c|c|c|c|c|c|}
\hline \multirow[b]{2}{*}{ Country } & \multicolumn{3}{|c|}{ Statistic } & \multicolumn{4}{|c|}{ Effect Size } \\
\hline & Order & $F$ & Asymptotic & Bootstrap & Estimate & Lower & Upper \\
\hline AUS & 2 & 3.59 & 0.0298 & 0.0540 & -0.0007 & -0.0277 & 0.0263 \\
\hline $\mathrm{CHI}$ & 5 & 7.84 & 0.0000 & 0.0000 & 0.0239 & 0.0031 & 0.0446 \\
\hline $\mathrm{HK}$ & 4 & 7.08 & 0.0000 & 0.0000 & 0.0634 & 0.0206 & 0.1062 \\
\hline IND & 5 & 5.59 & 0.0001 & 0.0000 & 0.0524 & 0.0176 & 0.0871 \\
\hline INO & 4 & 12.65 & 0.0000 & 0.0000 & 0.0456 & 0.0177 & 0.0735 \\
\hline JAP & 2 & 5.47 & 0.0050 & 0.0010 & -0.0027 & -0.0198 & 0.0145 \\
\hline SK & 4 & 4.26 & 0.0026 & 0.0200 & 0.0157 & -0.0202 & 0.0515 \\
\hline MAL & 4 & 8.14 & 0.0000 & 0.0000 & 0.0282 & 0.0053 & 0.0512 \\
\hline NZ & 2 & 1.42 & 0.2435 & 0.2980 & -0.0139 & -0.0365 & 0.0087 \\
\hline PAK & 1 & 6.43 & 0.0121 & 0.0290 & 0.0600 & 0.0136 & 0.1063 \\
\hline PHI & 1 & 3.58 & 0.0603 & 0.0450 & 0.0242 & -0.0009 & 0.0493 \\
\hline SIN & 7 & 3.73 & 0.0009 & 0.0030 & 0.0484 & 0.0111 & 0.0857 \\
\hline SRI & 2 & 1.96 & 0.1437 & 0.2510 & -0.0036 & -0.0194 & 0.0123 \\
\hline TAI & 2 & 12.55 & 0.0000 & 0.0000 & 0.0238 & 0.0056 & 0.0421 \\
\hline THA & 4 & 2.71 & 0.0318 & 0.0330 & 0.0112 & -0.0098 & 0.0323 \\
\hline $\mathrm{AUT}$ & 2 & 10.77 & 0.0000 & 0.0030 & -0.0189 & -0.0397 & 0.0020 \\
\hline BEL & 4 & 5.06 & 0.0007 & 0.0380 & -0.0029 & -0.0215 & 0.0158 \\
\hline $\mathrm{DEN}$ & 2 & 7.55 & 0.0007 & 0.0110 & 0.0011 & -0.0286 & 0.0308 \\
\hline FIN & 2 & 3.37 & 0.0368 & 0.0740 & 0.0122 & -0.0094 & 0.0338 \\
\hline FRA & 2 & 5.45 & 0.0051 & 0.0010 & 0.0058 & -0.0217 & 0.0334 \\
\hline CYP & 2 & 3.42 & 0.0350 & 0.0630 & -0.0029 & -0.0174 & 0.0117 \\
\hline $\mathrm{CZE}$ & 2 & 2.58 & 0.0790 & 0.1300 & 0.0097 & -0.0085 & 0.0280 \\
\hline GER & 2 & 4.96 & 0.0081 & 0.0030 & 0.0078 & -0.0165 & 0.0320 \\
\hline GRE & 2 & 0.45 & 0.6395 & 0.7970 & -0.0015 & -0.0247 & 0.0217 \\
\hline HUN & 2 & 3.85 & 0.0232 & 0.0180 & 0.0184 & -0.0105 & 0.0473 \\
\hline ITA & 2 & 3.54 & 0.0313 & 0.0650 & -0.0036 & -0.0279 & 0.0208 \\
\hline NLD & 2 & 7.17 & 0.0010 & 0.0200 & -0.0130 & -0.0416 & 0.0156 \\
\hline NOR & 2 & 11.03 & 0.0000 & 0.0010 & 0.0139 & -0.0114 & 0.0393 \\
\hline POL & 2 & 2.23 & 0.1104 & 0.0430 & 0.0055 & -0.0084 & 0.0194 \\
\hline POR & 2 & 7.78 & 0.0006 & 0.0000 & -0.0095 & -0.0294 & 0.0104 \\
\hline $\mathrm{ROM}$ & 3 & 3.81 & 0.0112 & 0.0170 & -0.0090 & -0.0266 & 0.0086 \\
\hline RUS & 1 & 0.83 & 0.3627 & 0.2680 & 0.0087 & -0.0100 & 0.0274 \\
\hline $\mathrm{ESP}$ & 1 & 0.26 & 0.6132 & 0.7270 & -0.0044 & -0.0214 & 0.0126 \\
\hline SWE & 2 & 6.97 & 0.0012 & 0.0010 & 0.0171 & -0.0067 & 0.0408 \\
\hline SWI & 2 & 2.79 & 0.0641 & 0.0880 & -0.0024 & -0.0222 & 0.0173 \\
\hline UK & 1 & 0.00 & 0.9706 & 0.4420 & 0.0007 & -0.0345 & 0.0358 \\
\hline US & 5 & 3.22 & 0.0084 & 0.0100 & 0.0182 & -0.0102 & 0.0466 \\
\hline
\end{tabular}

Notes: Countries: Australia (AUS), Austria (AUT), Belgium (BEL), China (CHI), Cyprus (CYP), Czech Republic (CZE), Denmark (DEN), France (FRA), Finland (FIN), Germany (GER), Greece (GRE), Hong Kong (HK), Hungary (HUN), India (IND), Indonesia (INO), Italy (ITA), Japan (JAP), Malaysia (MAL), Netherlands (NLD), New Zealand (NZ), Norway (NOR), Pakistan (PAK), Philippines (PHI), Poland (POL), Portugal (POR), Romania (ROM), Russia (RUS), Singapore (SIN), South Korea (SK), Spain (ESP), Sweden (SWE), Switzerland (SWI), Taiwan (TAI), Thailand (THA), Turkey (TUR). Order denotes the autoregressive order selected by SC; $F$ is the $F$-test statistic for $\left(\mathrm{H}_{0}: \beta_{1}=\cdots=\beta_{p}=0\right)$; Asymptotic and Bootstrap denote the $p$-value based on asymptotic and bootstrap approximations, respectively; Lower and Upper represent the lower and upper bounds of $95 \%$ confidence interval for effect size estimate $\left(\beta_{1}+\cdots+\beta_{p}\right)$. 
Table 5: Predictability of Asia-Pacific and European stock returns - DY predictor.

\begin{tabular}{|c|c|c|c|c|c|c|c|}
\hline \multirow[b]{2}{*}{ Country } & \multicolumn{3}{|c|}{ Statistic } & \multicolumn{4}{|c|}{ Effect Size } \\
\hline & Order & $F$ & Asymptotic & Bootstrap & Estimate & Lower & Upper \\
\hline AUS & 7 & 1.86 & 0.0786 & 0.1810 & -0.0017 & -0.0283 & 0.0248 \\
\hline $\mathrm{CHI}$ & 12 & 8.17 & 0.0000 & 0.0000 & 0.0196 & 0.0005 & 0.0387 \\
\hline $\mathrm{HK}$ & 8 & 4.64 & 0.0000 & 0.0010 & 0.0590 & 0.0176 & 0.1003 \\
\hline IND & 12 & 3.95 & 0.0000 & 0.0000 & 0.0507 & 0.0142 & 0.0872 \\
\hline INO & 7 & 7.66 & 0.0000 & 0.0000 & 0.0309 & -0.0002 & 0.0620 \\
\hline JAP & 8 & 1.75 & 0.0909 & 0.0890 & -0.0049 & -0.0233 & 0.0135 \\
\hline SK & 8 & 3.60 & 0.0007 & 0.0110 & 0.0258 & -0.0072 & 0.0588 \\
\hline MAL & 6 & 4.58 & 0.0002 & 0.0000 & 0.0096 & -0.0142 & 0.0334 \\
\hline $\mathrm{NZ}$ & 3 & 4.26 & 0.0063 & 0.0360 & -0.0194 & -0.0393 & 0.0006 \\
\hline PAK & 6 & 2.06 & 0.0601 & 0.0460 & 0.0316 & -0.0152 & 0.0785 \\
\hline PHI & 5 & 1.41 & 0.2243 & 0.1660 & 0.0072 & -0.0182 & 0.0327 \\
\hline SIN & 11 & 3.16 & 0.0007 & 0.0110 & 0.0362 & -0.0025 & 0.0750 \\
\hline SRI & 3 & 5.70 & 0.0010 & 0.0060 & -0.0116 & -0.0259 & 0.0026 \\
\hline TAI & 5 & 5.84 & 0.0001 & 0.0010 & 0.0176 & -0.0018 & 0.0371 \\
\hline THA & 12 & 3.18 & 0.0004 & 0.0030 & -0.0128 & -0.0357 & 0.0101 \\
\hline AUT & 6 & 8.32 & 0.0000 & 0.0010 & -0.0143 & -0.0322 & 0.0037 \\
\hline BEL & 3 & 7.52 & 0.0001 & 0.0050 & -0.0158 & -0.0325 & 0.0008 \\
\hline DEN & 4 & 4.46 & 0.0019 & 0.0090 & -0.0144 & -0.0399 & 0.0111 \\
\hline FIN & 12 & 3.41 & 0.0002 & 0.0590 & 0.0184 & -0.0095 & 0.0464 \\
\hline FRA & 7 & 3.48 & 0.0016 & 0.0040 & 0.0052 & -0.0227 & 0.0331 \\
\hline CYP & 2 & 8.62 & 0.0003 & 0.0020 & -0.0118 & -0.0253 & 0.0018 \\
\hline $\mathrm{CZE}$ & 2 & 7.38 & 0.0008 & 0.0040 & 0.0002 & -0.0159 & 0.0164 \\
\hline GER & 7 & 3.09 & 0.0044 & 0.0050 & 0.0039 & -0.0210 & 0.0287 \\
\hline GRE & 4 & 4.33 & 0.0023 & 0.0130 & -0.0158 & -0.0366 & 0.0051 \\
\hline HUN & 3 & 5.23 & 0.0018 & 0.0040 & -0.0031 & -0.0282 & 0.0220 \\
\hline ITA & 7 & 2.48 & 0.0191 & 0.0510 & -0.0044 & -0.0296 & 0.0208 \\
\hline NLD & 6 & 6.08 & 0.0000 & 0.0010 & -0.0045 & -0.0307 & 0.0217 \\
\hline NOR & 5 & 5.45 & 0.0001 & 0.0050 & 0.0035 & -0.0209 & 0.0279 \\
\hline POL & 4 & 2.09 & 0.0844 & 0.0450 & -0.0007 & -0.0147 & 0.0134 \\
\hline POR & 6 & 5.18 & 0.0001 & 0.0000 & -0.0137 & -0.0323 & 0.0050 \\
\hline ROM & 4 & 6.86 & 0.0000 & 0.0010 & -0.0118 & -0.0276 & 0.0039 \\
\hline RUS & 5 & 1.97 & 0.0860 & 0.1140 & 0.0001 & -0.0220 & 0.0221 \\
\hline $\mathrm{ESP}$ & 7 & 1.89 & 0.0739 & 0.1490 & -0.0094 & -0.0266 & 0.0078 \\
\hline SWE & 10 & 1.88 & 0.0515 & 0.0450 & 0.0118 & -0.0166 & 0.0403 \\
\hline SWI & 6 & 2.74 & 0.0145 & 0.0280 & -0.0047 & -0.0239 & 0.0145 \\
\hline UK & 7 & 2.17 & 0.0390 & 0.0900 & 0.0094 & -0.0244 & 0.0432 \\
\hline US & 10 & 2.33 & 0.0135 & 0.0200 & 0.0187 & -0.0127 & 0.0501 \\
\hline
\end{tabular}

Notes: Countries: Australia (AUS), Austria (AUT), Belgium (BEL), China (CHI), Cyprus (CYP), Czech Republic (CZE), Denmark (DEN), France (FRA), Finland (FIN), Germany (GER), Greece (GRE), Hong Kong (HK), Hungary (HUN), India (IND), Indonesia (INO), Italy (ITA), Japan (JAP), Malaysia (MAL), Netherlands (NLD), New Zealand (NZ), Norway (NOR), Pakistan (PAK), Philippines (PHI), Poland (POL), Portugal (POR), Romania (ROM), Russia (RUS), Singapore (SIN), South Korea (SK), Spain (ESP), Sweden (SWE), Switzerland (SWI), Taiwan (TAI), Thailand (THA), Turkey (TUR). Order denotes the autoregressive order selected by SC; $F$ is the $F$-test statistic for $\left(\mathrm{H}_{0}: \beta_{1}=\cdots=\beta_{p}=0\right)$; Asymptotic and Bootstrap denote the $p$-value based on asymptotic and bootstrap approximations, respectively; Lower and Upper represent the lower and upper bounds of $95 \%$ confidence interval for effect size estimate $\left(\beta_{1}+\cdots+\beta_{p}\right)$. 
Table 6: Predictability of Asia-Pacific and European stock returns - DE predictor.

\begin{tabular}{|c|c|c|c|c|c|c|c|}
\hline \multirow[b]{2}{*}{ Country } & \multicolumn{3}{|c|}{ Statistic } & \multicolumn{4}{|c|}{ Effect Size } \\
\hline & Order & $F$ & Asymptotic & Bootstrap & Estimate & Lower & Upper \\
\hline AUS & 2 & 2.49 & 0.0863 & 0.1090 & 0.0471 & -0.0040 & 0.0983 \\
\hline $\mathrm{CHI}$ & 2 & 0.42 & 0.6566 & 0.6910 & 0.0173 & -0.0206 & 0.0552 \\
\hline $\mathrm{HK}$ & 2 & 1.27 & 0.2838 & 0.4340 & 0.0356 & -0.0082 & 0.0793 \\
\hline IND & 2 & 6.08 & 0.0028 & 0.0010 & 0.1462 & 0.0630 & 0.2294 \\
\hline INO & 3 & 4.94 & 0.0026 & 0.0150 & 0.0318 & 0.0086 & 0.0550 \\
\hline JAP & 2 & 0.96 & 0.3838 & 0.2050 & -0.0286 & -0.0689 & 0.0118 \\
\hline SK & 2 & 0.48 & 0.6205 & 0.6380 & -0.0187 & -0.0710 & 0.0335 \\
\hline MAL & 2 & 11.41 & 0.0000 & 0.0000 & 0.0745 & 0.0439 & 0.1051 \\
\hline NZ & 1 & 0.03 & 0.8545 & 0.8200 & -0.0020 & -0.0228 & 0.0189 \\
\hline PAK & 3 & 5.35 & 0.0015 & 0.0180 & 0.0391 & -0.0223 & 0.1006 \\
\hline PHI & 2 & 2.72 & 0.0687 & 0.0500 & 0.0306 & 0.0037 & 0.0575 \\
\hline SIN & 2 & 7.11 & 0.0011 & 0.0060 & 0.0606 & 0.0250 & 0.0962 \\
\hline SRI & 1 & 0.38 & 0.5379 & 0.6050 & -0.0081 & -0.0338 & 0.0176 \\
\hline TAI & 2 & 2.12 & 0.1233 & 0.1980 & 0.0289 & 0.0009 & 0.0569 \\
\hline THA & 1 & 6.63 & 0.0109 & 0.0470 & 0.0252 & 0.0060 & 0.0444 \\
\hline $\mathrm{AUT}$ & 2 & 0.12 & 0.8870 & 0.8880 & 0.0052 & -0.0195 & 0.0299 \\
\hline BEL & 1 & 4.45 & 0.0364 & 0.0180 & 0.0251 & 0.0018 & 0.0484 \\
\hline $\mathrm{DEN}$ & 2 & 1.01 & 0.3670 & 0.4900 & 0.0079 & -0.0386 & 0.0543 \\
\hline FIN & 12 & 2.38 & 0.0075 & 0.5860 & 0.0813 & 0.0305 & 0.1321 \\
\hline FRA & 1 & 5.39 & 0.0215 & 0.0180 & 0.0484 & 0.0075 & 0.0892 \\
\hline CYP & 1 & 6.22 & 0.0136 & 0.0370 & 0.0205 & 0.0044 & 0.0366 \\
\hline $\mathrm{CZE}$ & 2 & 0.49 & 0.6159 & 0.7120 & 0.0094 & -0.0194 & 0.0383 \\
\hline GER & 2 & 0.49 & 0.6127 & 0.5550 & 0.0081 & -0.0182 & 0.0344 \\
\hline GRE & 4 & 0.64 & 0.6364 & 0.7290 & -0.0052 & -0.0240 & 0.0136 \\
\hline HUN & 1 & 0.07 & 0.7935 & 0.7770 & 0.0047 & -0.0302 & 0.0395 \\
\hline ITA & 2 & 3.71 & 0.0264 & 0.0400 & 0.0832 & 0.0231 & 0.1433 \\
\hline NLD & 2 & 0.79 & 0.4561 & 0.4460 & 0.0191 & -0.0129 & 0.0511 \\
\hline NOR & 1 & 6.73 & 0.0103 & 0.0220 & 0.0519 & 0.0127 & 0.0912 \\
\hline POL & 2 & 3.82 & 0.0237 & 0.0230 & 0.0202 & 0.0038 & 0.0365 \\
\hline POR & 2 & 1.78 & 0.1723 & 0.3620 & -0.0070 & -0.0322 & 0.0183 \\
\hline $\mathrm{ROM}$ & 2 & 0.06 & 0.9402 & 0.9080 & -0.0035 & -0.0416 & 0.0346 \\
\hline RUS & 3 & 0.23 & 0.8738 & 0.8980 & 0.0067 & -0.0129 & 0.0264 \\
\hline $\mathrm{ESP}$ & 1 & 5.78 & 0.0172 & 0.0180 & 0.0341 & 0.0063 & 0.0619 \\
\hline SWE & 3 & 2.49 & 0.0620 & 0.0840 & 0.0386 & -0.0013 & 0.0786 \\
\hline SWI & 2 & 1.10 & 0.3339 & 0.5210 & 0.0158 & -0.0075 & 0.0391 \\
\hline UK & 1 & 1.23 & 0.2687 & 0.2690 & -0.0211 & -0.0583 & 0.0162 \\
\hline US & 4 & 0.27 & 0.8968 & 0.9190 & 0.0246 & -0.0443 & 0.0934 \\
\hline
\end{tabular}

Notes: Countries: Australia (AUS), Austria (AUT), Belgium (BEL), China (CHI), Cyprus (CYP), Czech Republic (CZE), Denmark (DEN), France (FRA), Finland (FIN), Germany (GER), Greece (GRE), Hong Kong (HK), Hungary (HUN), India (IND), Indonesia (INO), Italy (ITA), Japan (JAP), Malaysia (MAL), Netherlands (NLD), New Zealand (NZ), Norway (NOR), Pakistan (PAK), Philippines (PHI), Poland (POL), Portugal (POR), Romania (ROM), Russia (RUS), Singapore (SIN), South Korea (SK), Spain (ESP), Sweden (SWE), Switzerland (SWI), Taiwan (TAI), Thailand (THA), Turkey (TUR). Order denotes the autoregressive order selected by SC; $F$ is the $F$-test statistic for $\left(\mathrm{H}_{0}: \beta_{1}=\cdots=\beta_{p}=0\right)$; Asymptotic and Bootstrap denote the $p$-value based on asymptotic and bootstrap approximations, respectively; Lower and Upper represent the lower and upper bounds of $95 \%$ confidence interval for effect size estimate $\left(\beta_{1}+\cdots+\beta_{p}\right)$. 
Table 7: Predictability of Asia-Pacific and European stock returns - EP predictor.

\begin{tabular}{|c|c|c|c|c|c|c|c|}
\hline \multirow[b]{2}{*}{ Country } & \multicolumn{3}{|c|}{ Statistic } & \multicolumn{4}{|c|}{ Effect Size } \\
\hline & Order & $F$ & Asymptotic & Bootstrap & Estimate & Lower & Upper \\
\hline AUS & 2 & 1.75 & 0.1774 & 0.3610 & -0.0115 & -0.0417 & 0.0187 \\
\hline $\mathrm{CHI}$ & 2 & 20.24 & 0.0000 & 0.0000 & -0.0023 & -0.0200 & 0.0155 \\
\hline $\mathrm{HK}$ & 2 & 8.10 & 0.0004 & 0.0110 & 0.0074 & -0.0251 & 0.0398 \\
\hline IND & 5 & 5.05 & 0.0002 & 0.0010 & 0.0355 & -0.0057 & 0.0766 \\
\hline INO & 4 & 4.82 & 0.0010 & 0.0130 & -0.0021 & -0.0360 & 0.0318 \\
\hline JAP & 2 & 3.11 & 0.0470 & 0.0060 & 0.0082 & -0.0081 & 0.0246 \\
\hline SK & 4 & 6.76 & 0.0000 & 0.0000 & 0.0365 & -0.0033 & 0.0763 \\
\hline MAL & 2 & 7.97 & 0.0005 & 0.0030 & -0.0065 & -0.0372 & 0.0243 \\
\hline $\mathrm{NZ}$ & 1 & 1.10 & 0.2960 & 0.4180 & -0.0115 & -0.0329 & 0.0100 \\
\hline PAK & 2 & 4.32 & 0.0149 & 0.0330 & 0.0223 & -0.0176 & 0.0621 \\
\hline PHI & 2 & 0.28 & 0.7524 & 0.6220 & 0.0052 & -0.0320 & 0.0425 \\
\hline SIN & 2 & 15.59 & 0.0000 & 0.0020 & -0.0130 & -0.0369 & 0.0109 \\
\hline SRI & 2 & 7.66 & 0.0007 & 0.0050 & -0.0052 & -0.0235 & 0.0131 \\
\hline TAI & 2 & 9.47 & 0.0001 & 0.0010 & 0.0275 & 0.0017 & 0.0533 \\
\hline THA & 2 & 3.46 & 0.0335 & 0.0780 & 0.0016 & -0.0318 & 0.0351 \\
\hline AUT & 2 & 10.08 & 0.0001 & 0.0030 & -0.0354 & -0.0636 & -0.0072 \\
\hline BEL & 2 & 14.41 & 0.0000 & 0.0000 & -0.0404 & -0.0643 & -0.0166 \\
\hline DEN & 2 & 2.59 & 0.0781 & 0.1090 & 0.0005 & -0.0333 & 0.0342 \\
\hline FIN & 11 & 2.29 & 0.0124 & 0.3170 & 0.0283 & -0.0157 & 0.0722 \\
\hline FRA & 2 & 4.20 & 0.0166 & 0.0210 & -0.0155 & -0.0454 & 0.0144 \\
\hline CYP & 11 & 3.00 & 0.0012 & 0.0040 & 0.0199 & -0.0359 & -0.0040 \\
\hline $\mathrm{CZE}$ & 5 & 1.47 & 0.2012 & 0.2030 & -0.0010 & -0.0245 & 0.0225 \\
\hline GER & 2 & 2.56 & 0.0804 & 0.0410 & 0.0107 & -0.0200 & 0.0413 \\
\hline GRE & 1 & 0.05 & 0.8218 & 0.8670 & -0.0027 & -0.0259 & 0.0205 \\
\hline HUN & 2 & 4.89 & 0.0086 & 0.0110 & 0.0310 & -0.0094 & 0.0715 \\
\hline ITA & 2 & 4.13 & 0.0177 & 0.0560 & -0.0143 & -0.0406 & 0.0121 \\
\hline NLD & 2 & 4.33 & 0.0147 & 0.0590 & -0.0221 & -0.0486 & 0.0045 \\
\hline NOR & 2 & 4.89 & 0.0087 & 0.0140 & -0.0116 & -0.0388 & 0.0157 \\
\hline POL & 2 & 5.98 & 0.0031 & 0.0030 & -0.0097 & -0.0323 & 0.0128 \\
\hline POR & 2 & 16.67 & 0.0000 & 0.0000 & 0.0011 & -0.0219 & 0.0242 \\
\hline ROM & 4 & 1.58 & 0.1817 & 0.2230 & -0.0053 & -0.0282 & 0.0176 \\
\hline RUS & 4 & 5.43 & 0.0004 & 0.0060 & 0.0189 & -0.0083 & 0.0461 \\
\hline $\mathrm{ESP}$ & 2 & 5.04 & 0.0075 & 0.0880 & -0.0234 & -0.0470 & 0.0002 \\
\hline SWE & 2 & 4.99 & 0.0079 & 0.0080 & 0.0116 & -0.0129 & 0.0361 \\
\hline SWI & 2 & 2.15 & 0.1201 & 0.3480 & -0.0256 & -0.0667 & 0.0154 \\
\hline UK & 2 & 3.06 & 0.0496 & 0.0330 & 0.0037 & -0.0196 & 0.0270 \\
\hline US & 2 & 3.10 & 0.0477 & 0.0520 & 0.0147 & -0.0138 & 0.0433 \\
\hline
\end{tabular}

Notes: Countries: Australia (AUS), Austria (AUT), Belgium (BEL), China (CHI), Cyprus (CYP), Czech Republic (CZE), Denmark (DEN), France (FRA), Finland (FIN), Germany (GER), Greece (GRE), Hong Kong (HK), Hungary (HUN), India (IND), Indonesia (INO), Italy (ITA), Japan (JAP), Malaysia (MAL), Netherlands (NLD), New Zealand (NZ), Norway (NOR), Pakistan (PAK), Philippines (PHI), Poland (POL), Portugal (POR), Romania (ROM), Russia (RUS), Singapore (SIN), South Korea (SK), Spain (ESP), Sweden (SWE), Switzerland (SWI), Taiwan (TAI), Thailand (THA), Turkey (TUR). Order denotes the autoregressive order selected by SC; $F$ is the $F$-test statistic for $\left(\mathrm{H}_{0}: \beta_{1}=\cdots=\beta_{p}=0\right)$; Asymptotic and Bootstrap denote the $p$-value based on asymptotic and bootstrap approximations, respectively; Lower and Upper represent the lower and upper bounds of $95 \%$ confidence interval for effect size estimate $\left(\beta_{1}+\cdots+\beta_{p}\right)$. 
Table 8: Predictability of Asia-Pacific and European stock returns - PRES predictor.

\begin{tabular}{|c|c|c|c|c|c|c|c|}
\hline \multirow[b]{2}{*}{ Country } & \multicolumn{3}{|c|}{ Statistic } & \multicolumn{4}{|c|}{ Effect Size } \\
\hline & Order & $F$ & Asymptotic & Bootstrap & Estimate & Lower & Upper \\
\hline AUS & 1 & 63.68 & 0.0000 & 0.0000 & 0.1145 & 0.0863 & 0.1426 \\
\hline $\mathrm{CHI}$ & 2 & 28.04 & 0.0000 & 0.0000 & 0.1190 & 0.0776 & 0.1605 \\
\hline HK & 2 & 35.00 & 0.0000 & 0.0000 & 0.1482 & 0.1047 & 0.1917 \\
\hline IND & 2 & 56.76 & 0.0000 & 0.0000 & 0.2013 & 0.1511 & 0.2515 \\
\hline INO & 1 & 125.65 & 0.0000 & 0.0000 & 0.1834 & 0.1514 & 0.2155 \\
\hline JAP & 1 & 80.96 & 0.0000 & 0.0000 & 0.1563 & 0.1223 & 0.1904 \\
\hline SK & 2 & 24.51 & 0.0000 & 0.0000 & 0.1601 & 0.1049 & 0.2153 \\
\hline MAL & 3 & 43.71 & 0.0000 & 0.0000 & 0.1329 & 0.1039 & 0.1619 \\
\hline $\mathrm{NZ}$ & 1 & 92.66 & 0.0000 & 0.0000 & 0.0840 & 0.0669 & 0.1010 \\
\hline PAK & 1 & 183.60 & 0.0000 & 0.0000 & 0.1521 & 0.1301 & 0.1741 \\
\hline PHI & 1 & 73.14 & 0.0000 & 0.0000 & 0.1131 & 0.0872 & 0.1391 \\
\hline SIN & 1 & 94.89 & 0.0000 & 0.0000 & 0.1244 & 0.0994 & 0.1495 \\
\hline SRI & 1 & 88.77 & 0.0000 & 0.0000 & 0.1149 & 0.0910 & 0.1388 \\
\hline TAI & 1 & 63.46 & 0.0000 & 0.0000 & 0.1230 & 0.0927 & 0.1533 \\
\hline THA & 1 & 55.53 & 0.0000 & 0.0000 & 0.1193 & 0.0879 & 0.1506 \\
\hline AUT & 1 & 73.10 & 0.0000 & 0.0000 & 0.1511 & 0.1165 & 0.1857 \\
\hline BEL & 1 & 65.16 & 0.0000 & 0.0000 & 0.1438 & 0.1089 & 0.1787 \\
\hline DEN & 1 & 64.13 & 0.0000 & 0.0000 & 0.1288 & 0.0973 & 0.1604 \\
\hline FIN & 3 & 7.16 & 0.0001 & 0.0000 & 0.0928 & 0.0214 & 0.1641 \\
\hline FRA & 2 & 26.71 & 0.0000 & 0.0000 & 0.1124 & 0.0695 & 0.1554 \\
\hline CYP & 1 & 92.24 & 0.0000 & 0.0000 & 0.1944 & 0.1547 & 0.2340 \\
\hline $\mathrm{CZE}$ & 2 & 20.94 & 0.0000 & 0.0000 & 0.0875 & 0.0502 & 0.1247 \\
\hline GER & 2 & 32.61 & 0.0000 & 0.0000 & 0.1669 & 0.1181 & 0.2158 \\
\hline GRE & 1 & 98.92 & 0.0000 & 0.0000 & 0.1587 & 0.1274 & 0.1900 \\
\hline HUN & 1 & 60.54 & 0.0000 & 0.0000 & 0.1785 & 0.1335 & 0.2234 \\
\hline ITA & 3 & 8.40 & 0.0000 & 0.0000 & 0.0398 & -0.0117 & 0.0914 \\
\hline NLD & 1 & 52.20 & 0.0000 & 0.0000 & 0.1357 & 0.0989 & 0.1725 \\
\hline NOR & 1 & 72.67 & 0.0000 & 0.0000 & 0.1479 & 0.1139 & 0.1819 \\
\hline POL & 3 & 20.73 & 0.0000 & 0.0000 & 0.1466 & 0.0966 & 0.1966 \\
\hline POR & 1 & 79.82 & 0.0000 & 0.0000 & 0.1158 & 0.0904 & 0.1413 \\
\hline ROM & 1 & 39.33 & 0.0000 & 0.0000 & 0.1416 & 0.0973 & 0.1858 \\
\hline RUS & 4 & 3.90 & 0.0047 & 0.0190 & 0.0218 & 0.0027 & 0.0409 \\
\hline ESP & 5 & 3.68 & 0.0035 & 0.0080 & 0.0135 & 0.0010 & 0.0261 \\
\hline SWE & 3 & 14.66 & 0.0000 & 0.0000 & 0.0984 & 0.0493 & 0.1475 \\
\hline SWI & 1 & 52.77 & 0.0000 & 0.0000 & 0.0984 & 0.0718 & 0.1249 \\
\hline UK & 1 & 27.58 & 0.0000 & 0.0000 & 0.0748 & 0.0469 & 0.1027 \\
\hline US & 1 & 42.57 & 0.0000 & 0.0000 & 0.1006 & 0.0704 & 0.1309 \\
\hline
\end{tabular}

Notes: Countries: Australia (AUS), Austria (AUT), Belgium (BEL), China (CHI), Cyprus (CYP), Czech Republic (CZE), Denmark (DEN), France (FRA), Finland (FIN), Germany (GER), Greece (GRE), Hong Kong (HK), Hungary (HUN), India (IND), Indonesia (INO), Italy (ITA), Japan (JAP), Malaysia (MAL), Netherlands (NLD), New Zealand (NZ), Norway (NOR), Pakistan (PAK), Philippines (PHI), Poland (POL), Portugal (POR), Romania (ROM), Russia (RUS), Singapore (SIN), South Korea (SK), Spain (ESP), Sweden (SWE), Switzerland (SWI), Taiwan (TAI), Thailand (THA), Turkey (TUR). Order denotes the autoregressive order selected by SC; $F$ is the $F$-test statistic for $\left(\mathrm{H}_{0}: \beta_{1}=\cdots=\beta_{p}=0\right)$; Asymptotic and Bootstrap denote the $p$-value based on asymptotic and bootstrap approximations, respectively; Lower and Upper represent the lower and upper bounds of $95 \%$ confidence interval for effect size estimate $\left(\beta_{1}+\cdots+\beta_{p}\right)$. 
Table 9: Predictability of Asia-Pacific and European stock returns - CVm predictor.

\begin{tabular}{|c|c|c|c|c|c|c|c|}
\hline \multirow[b]{2}{*}{ Country } & \multicolumn{3}{|c|}{ Statistic } & \multicolumn{4}{|c|}{ Effect Size } \\
\hline & Order & $F$ & Asymptotic & Bootstrap & Estimate & Lower & Upper \\
\hline AUS & 2 & 2.17 & 0.1178 & 0.0720 & 0.0400 & -0.0055 & 0.0855 \\
\hline $\mathrm{CHI}$ & 1 & 9.70 & 0.0022 & 0.0010 & 0.0262 & 0.0097 & 0.0427 \\
\hline HK & 5 & 2.90 & 0.0154 & 0.0240 & 0.0648 & -0.0466 & 0.1761 \\
\hline \multicolumn{8}{|l|}{ IND } \\
\hline INO & 1 & 3.93 & 0.0489 & 0.1630 & 0.0192 & 0.0002 & 0.0382 \\
\hline JAP & 1 & 3.18 & 0.0763 & 0.1040 & 0.0394 & -0.0039 & 0.0826 \\
\hline SK & 1 & 0.01 & 0.9251 & 0.9340 & -0.0015 & -0.0327 & 0.0297 \\
\hline MAL & 1 & 10.6 & 0.0014 & 0.0160 & 0.0254 & 0.0101 & 0.0408 \\
\hline $\mathrm{NZ}$ & 3 & 0.55 & 0.6464 & 0.5610 & -0.0208 & -0.0597 & 0.0182 \\
\hline \multicolumn{8}{|l|}{ PAK } \\
\hline PHI & 1 & 1.77 & 0.1218 & 0.0590 & 0.0657 & 0.0191 & 0.1123 \\
\hline SIN & 2 & 0.15 & 0.8613 & 0.8520 & -0.0098 & -0.0551 & 0.0355 \\
\hline \multicolumn{8}{|l|}{ SRI } \\
\hline TAI & 1 & 5.62 & 0.0188 & 0.0600 & 0.0366 & 0.0063 & 0.0668 \\
\hline THA & 1 & 0.80 & 0.3717 & 0.3570 & 0.0050 & -0.0060 & 0.0160 \\
\hline AUT & 1 & 2.23 & 0.1374 & 0.3220 & -0.0204 & -0.0473 & 0.0064 \\
\hline BEL & 1 & 11.54 & 0.0008 & 0.0470 & -0.0456 & -0.0718 & -0.0193 \\
\hline DEN & 2 & 0.53 & 0.5900 & 0.5700 & -0.0266 & -0.0780 & 0.0248 \\
\hline FIN & 2 & 0.32 & 0.7243 & 0.7020 & 0.0182 & -0.0396 & 0.0760 \\
\hline FRA & 3 & 1.18 & 0.3208 & 0.3270 & 0.0033 & -0.0701 & 0.0768 \\
\hline CYP & 1 & 5.54 & 0.0198 & 0.0060 & 0.0269 & 0.0045 & 0.0493 \\
\hline $\mathrm{CZE}$ & 2 & 3.59 & 0.0296 & 0.1330 & -0.0062 & -0.0357 & 0.0233 \\
\hline GER & 1 & 1.68 & 0.1967 & 0.3500 & -0.0139 & -0.0349 & 0.0071 \\
\hline GRE & 3 & 0.98 & 0.4030 & 0.4910 & -0.0105 & -0.0696 & 0.0486 \\
\hline HUN & 1 & 0.57 & 0.4512 & 0.4930 & -0.0112 & -0.0403 & 0.0179 \\
\hline ITA & 3 & 0.55 & 0.6495 & 0.5570 & 0.0409 & -0.0270 & 0.1088 \\
\hline NLD & 2 & 2.18 & 0.1161 & 0.1630 & -0.0231 & -0.0780 & 0.0317 \\
\hline NOR & 1 & 1.36 & 0.2452 & 0.3490 & -0.0163 & -0.0438 & 0.0111 \\
\hline POL & 1 & 3.41 & 0.0665 & 0.0670 & 0.0240 & -0.0015 & 0.0494 \\
\hline POR & 2 & 2.80 & 0.0633 & 0.0180 & 0.0310 & 0.0042 & 0.0578 \\
\hline $\mathrm{ROM}$ & 1 & 1.26 & 0.2635 & 0.2310 & 0.0098 & -0.0073 & 0.0268 \\
\hline RUS & 1 & 0.61 & 0.4374 & 0.3110 & 0.0012 & -0.0018 & 0.0041 \\
\hline ESP & 3 & 1.05 & 0.3717 & 0.4170 & 0.0305 & -0.0469 & 0.1080 \\
\hline SWE & 2 & 1.29 & 0.2789 & 0.4000 & -0.0037 & -0.0541 & 0.0467 \\
\hline SWI & 1 & 4.96 & 0.0273 & 0.0800 & -0.0272 & -0.0511 & -0.0033 \\
\hline UK & 3 & 0.55 & 0.6485 & 0.6790 & -0.0271 & -0.0999 & 0.0456 \\
\hline US & 1 & 4.98 & 0.0269 & 0.1560 & -0.0463 & -0.0870 & -0.0056 \\
\hline
\end{tabular}

Notes: Countries: Australia (AUS), Austria (AUT), Belgium (BEL), China (CHI), Cyprus (CYP), Czech Republic (CZE), Denmark (DEN), France (FRA), Finland (FIN), Germany (GER), Greece (GRE), Hong Kong (HK), Hungary (HUN), India (IND), Indonesia (INO), Italy (ITA), Japan (JAP), Malaysia (MAL), Netherlands (NLD), New Zealand (NZ), Norway (NOR), Pakistan (PAK), Philippines (PHI), Poland (POL), Portugal (POR), Romania (ROM), Russia (RUS), Singapore (SIN), South Korea (SK), Spain (ESP), Sweden (SWE), Switzerland (SWI), Taiwan (TAI), Thailand (THA), Turkey (TUR). Order denotes the autoregressive order selected by SC; $F$ is the $F$-test statistic for $\left(\mathrm{H}_{0}: \beta_{1}=\cdots=\beta_{p}=0\right)$; Asymptotic and Bootstrap denote the $p$-value based on asymptotic and bootstrap approximations, respectively; Lower and Upper represent the lower and upper bounds of $95 \%$ confidence interval for effect size estimate $\left(\beta_{1}+\cdots+\beta_{p}\right)$. 
Table 10: Predictability of Asia-Pacific and European stock returns - STIR predictor.

\begin{tabular}{|c|c|c|c|c|c|c|c|}
\hline \multirow[b]{2}{*}{ Country } & \multicolumn{3}{|c|}{ Statistic } & \multicolumn{4}{|c|}{ Effect Size } \\
\hline & Order & $F$ & Asymptotic & Bootstrap & Estimate & Lower & Upper \\
\hline AUS & 2 & 4.14 & 0.0176 & 0.0170 & -0.4016 & -0.8472 & 0.0440 \\
\hline \multicolumn{8}{|l|}{ CHI } \\
\hline HK & 1 & 0.05 & 0.8202 & 0.8590 & -0.0513 & -0.4931 & 0.3905 \\
\hline \multicolumn{8}{|l|}{ IND } \\
\hline INO & 2 & 1.76 & 0.1755 & 0.2950 & -0.2738 & -0.5620 & 0.0143 \\
\hline JAP & 1 & 0.06 & 0.8080 & 0.8210 & -0.3415 & -2.4088 & 0.0031 \\
\hline SK & 2 & 4.45 & 0.0131 & 0.0150 & -1.2369 & -2.0805 & -0.3932 \\
\hline MAL & 1 & 4.93 & 0.0277 & 0.0330 & -1.5983 & -3.0088 & -0.1879 \\
\hline $\mathrm{NZ}$ & 2 & 1.93 & 0.1488 & 0.2820 & -0.2049 & -0.4168 & 0.0070 \\
\hline \multicolumn{8}{|l|}{ PAK } \\
\hline PHI & 12 & 3.19 & 0.0004 & 0.0220 & -0.1571 & -0.5307 & 0.2165 \\
\hline \multicolumn{8}{|l|}{ SIN } \\
\hline \multicolumn{8}{|l|}{ SRI } \\
\hline \multicolumn{8}{|l|}{ TAI } \\
\hline THA & 8 & 2.11 & 0.0378 & 0.1800 & -0.8715 & -1.7685 & 0.0255 \\
\hline AUT & 2 & 4.64 & 0.0109 & 0.0430 & -0.8086 & -1.3287 & -0.2884 \\
\hline BEL & 2 & 7.35 & 0.0009 & 0.0020 & -0.8708 & -1.3307 & -0.4109 \\
\hline DEN & 2 & 7.45 & 0.0008 & 0.0080 & -0.8792 & -1.3285 & -0.4298 \\
\hline FIN & 2 & 6.51 & 0.0019 & 0.0090 & -1.2162 & -1.8801 & -0.5523 \\
\hline FRA & 3 & 4.03 & 0.0085 & 0.0030 & -0.7314 & -1.1619 & -0.3009 \\
\hline \multicolumn{8}{|l|}{ CYP } \\
\hline CZE & 2 & 1.93 & 0.1482 & 0.3970 & -0.5106 & -1.0232 & 0.0020 \\
\hline GER & 2 & 8.37 & 0.0003 & 0.0000 & -0.9443 & -1.3976 & -0.4910 \\
\hline GRE & 2 & 4.53 & 0.0121 & 0.0050 & -1.0311 & -1.7275 & -0.3348 \\
\hline HUN & 1 & 0.09 & 0.7701 & 0.5040 & 0.0571 & -0.3253 & 0.4395 \\
\hline ITA & 1 & 9.42 & 0.0025 & 0.0010 & -0.9348 & -1.5317 & -0.3379 \\
\hline NLD & 2 & 7.94 & 0.0005 & 0.0030 & -1.0237 & -1.5297 & -0.5177 \\
\hline NOR & 3 & 9.43 & 0.0000 & 0.0160 & -0.8845 & -1.2643 & -0.5047 \\
\hline POL & 4 & 3.33 & 0.0117 & 0.0290 & -0.2526 & -0.4239 & -0.0814 \\
\hline POR & 2 & 6.61 & 0.0017 & 0.0090 & -0.7990 & -1.2339 & -0.3640 \\
\hline $\mathrm{ROM}$ & 11 & 1.58 & 0.1101 & 0.2510 & -0.0542 & -0.1821 & 0.0737 \\
\hline RUS & 1 & 1.97 & 0.1618 & 0.2150 & 0.2644 & -0.1044 & 0.6332 \\
\hline ESP & 2 & 4.15 & 0.0174 & 0.0350 & -0.8689 & -1.4845 & -0.2533 \\
\hline SWE & 3 & 10.98 & 0.0000 & 0.0000 & -1.4530 & -1.9947 & -0.9114 \\
\hline SWI & 2 & 4.16 & 0.0173 & 0.0040 & -0.6731 & -1.1921 & -0.1542 \\
\hline UK & 2 & 1.57 & 0.2107 & 0.0800 & -0.2246 & -0.5011 & 0.0519 \\
\hline US & 3 & 1.39 & 0.2473 & 0.3500 & -0.2147 & -0.5326 & 0.1032 \\
\hline
\end{tabular}

Notes: Countries: Australia (AUS), Austria (AUT), Belgium (BEL), China (CHI), Cyprus (CYP), Czech Republic (CZE), Denmark (DEN), France (FRA), Finland (FIN), Germany (GER), Greece (GRE), Hong Kong (HK), Hungary (HUN), India (IND), Indonesia (INO), Italy (ITA), Japan (JAP), Malaysia (MAL), Netherlands (NLD), New Zealand (NZ), Norway (NOR), Pakistan (PAK), Philippines (PHI), Poland (POL), Portugal (POR), Romania (ROM), Russia (RUS), Singapore (SIN), South Korea (SK), Spain (ESP), Sweden (SWE), Switzerland (SWI), Taiwan (TAI), Thailand (THA), Turkey (TUR). Order denotes the autoregressive order selected by SC; $F$ is the $F$-test statistic for $\left(\mathrm{H}_{0}: \beta_{1}=\cdots=\beta_{p}=0\right)$; Asymptotic and Bootstrap denote the $p$-value based on asymptotic and bootstrap approximations, respectively; Lower and Upper represent the lower and upper bounds of $95 \%$ confidence interval for effect size estimate $\left(\beta_{1}+\cdots+\beta_{p}\right)$. 
Table 11: Theil's U values for out-of-sample forecasting accuracy.

\begin{tabular}{lcccccc}
\hline \hline & \multicolumn{2}{c}{ Asia-Pacific } & \multicolumn{2}{c}{ Europe } & \multicolumn{2}{c}{ US } \\
& $\begin{array}{c}\text { Improved } \\
\text { ARM }\end{array}$ & EGLS & $\begin{array}{c}\text { Improved } \\
\text { ARM }\end{array}$ & EGLS & $\begin{array}{c}\text { Improved } \\
\text { ARM }\end{array}$ & EGLS \\
\hline DP & 0.68 & 0.69 & 0.73 & 0.73 & 0.55 & 0.55 \\
DY & 0.67 & 0.68 & 0.71 & 0.72 & 0.61 & 0.63 \\
DE & 0.71 & 0.71 & 0.78 & 0.78 & 0.82 & 0.83 \\
EP & 0.73 & 0.73 & 0.73 & 0.73 & 0.67 & 0.67 \\
PRES & 0.50 & 0.50 & 0.64 & 0.64 & 0.47 & 0.47 \\
CVm & 0.77 & 0.77 & 0.80 & 0.78 & 0.75 & 0.74 \\
STIR & 0.65 & 0.65 & 0.58 & 0.56 & 0.62 & 0.60 \\
\hline \hline
\end{tabular}

Notes: The entries for the Asia-Pacific and European stock markets are the median values of 15 and 21 Asia-Pacific and European markets, respectively (not including US). 
Table 12: MCS test for out-of-sample forecasting accuracy from IARM approach.

\begin{tabular}{|c|c|c|c|c|c|c|c|}
\hline Country & DP & DY & $\mathrm{DE}$ & $\mathrm{EP}$ & PRES & $\mathrm{CVm}$ & STIR \\
\hline AUS & $0.476^{*}$ & $0.316^{*}$ & $0.476^{*}$ & $0.473^{*}$ & 0.574 & $0.476^{*}$ & 1.000 \\
\hline $\mathrm{CHI}$ & $0.090^{* * *}$ & 0.848 & 0.577 & 0.420 & 1.000 & 0.875 & - \\
\hline HK & 0.803 & 0.503 & $0.430^{*}$ & 1.000 & 0.957 & 0.900 & 0.957 \\
\hline IND & 0.816 & 0.749 & 0.816 & 0.807 & 1.000 & - & - \\
\hline INO & 1.000 & 0.578 & 0.502 & 0.751 & 0.751 & 0.751 & 0.695 \\
\hline JAP & $0.154^{* *}$ & $0.137^{* *}$ & $0.158^{* *}$ & $0.154^{* *}$ & 1.000 & $0.154^{* *}$ & $0.137^{* *}$ \\
\hline SK & 0.543 & $0.124^{* *}$ & 0.832 & 0.610 & $0.124^{* *}$ & 1.000 & $0.007^{* * *}$ \\
\hline MAL & 0.855 & 0.855 & 0.855 & 0.855 & 0.855 & 1.000 & 0.855 \\
\hline $\mathrm{NZ}$ & $0.301^{*}$ & $0.009^{* * *}$ & 0.573 & $0.134^{* *}$ & 1.000 & 0.668 & 0.728 \\
\hline PAK & $0.269^{*}$ & 1.000 & $0.164^{* *}$ & 0.636 & $0.263^{*}$ & - & - \\
\hline PHI & 0.568 & 0.568 & $0.497^{*}$ & $0.324^{*}$ & 1.000 & 0.568 & 0.642 \\
\hline SIN & 0.877 & 0.869 & 0.869 & 0.830 & 1.000 & 0.877 & - \\
\hline SRI & 0.516 & 0.516 & 0.516 & $0.470^{*}$ & 1.000 & - & - \\
\hline TAI & 0.720 & 0.720 & 1.000 & $0.493^{*}$ & 0.720 & 0.624 & - \\
\hline THA & $0.446^{*}$ & $0.380^{*}$ & $0.446^{*}$ & $0.446^{*}$ & 1.000 & $0.446^{*}$ & $0446^{*}$ \\
\hline AUT & $0.038^{* * *}$ & $0.009^{* * *}$ & 0.632 & $0.006^{* * *}$ & $0.006^{* * *}$ & 1.000 & $0.428^{*}$ \\
\hline BEL & 0.990 & 0.9995 & 0.654 & 0.880 & 0.786 & 0.995 & 1.000 \\
\hline CYP & 0.572 & 0.572 & 0.572 & 0.572 & 1.000 & 0.572 & - \\
\hline CZE & 0.645 & 0.645 & 0.645 & 0.645 & 1.000 & 0.645 & $0.239^{*}$ \\
\hline DEN & 0.562 & 0.562 & 0.562 & 0.562 & 0.528 & 0.562 & 1.000 \\
\hline FIN & $0.401^{*}$ & $0.147^{* *}$ & $0.432^{*}$ & $0.099^{* * *}$ & $0.004^{* * *}$ & $0.119^{* *}$ & 1.000 \\
\hline FRA & $0.033^{* * *}$ & $0.009^{* * *}$ & $0.089^{* * *}$ & $0.014^{* * *}$ & $0.015^{* * *}$ & $0.010^{* * *}$ & 1.000 \\
\hline GER & $0.426^{*}$ & $0.426^{*}$ & $0.426^{*}$ & $0.426^{*}$ & $0.189^{* *}$ & $0.421^{*}$ & 1.000 \\
\hline GRE & $0.048^{* * *}$ & $0.048^{* * *}$ & $0.048^{* * *}$ & $0.048^{* * *}$ & 1.000 & $0.048^{* * *}$ & $0.048^{* * *}$ \\
\hline HUN & $0.003^{* * *}$ & 1.000 & $0.258^{*}$ & $0.057^{* *}$ & $0.007^{* * *}$ & $0.026^{* * *}$ & $0.246^{*}$ \\
\hline ITA & $0.330^{*}$ & $0.458^{*}$ & 0.741 & $0.313^{*}$ & $0.001^{* * *}$ & $0.037^{* * *}$ & 1.000 \\
\hline NLD & 0.607 & $0.070^{* * *}$ & 0.533 & 0.607 & $0.155^{* *}$ & $0.155^{* *}$ & 1.000 \\
\hline NOR & $0.428^{*}$ & $0.385^{*}$ & 1.000 & $0.418^{*}$ & $0.058^{* * *}$ & 0.428 & 0.510 \\
\hline POL & 1.000 & $0.429^{*}$ & 0.928 & $0.274^{*}$ & 0.848 & 0.716 & 0.992 \\
\hline POR & $0.028^{* * *}$ & $0.165^{* *}$ & $0.028^{* * *}$ & $0.062^{* * *}$ & 0.505 & $0.027^{* * *}$ & 1.000 \\
\hline ROM & $0.184^{* *}$ & $0.113^{* *}$ & 1.000 & $0.127^{* *}$ & 0.527 & $0.250^{*}$ & $0.112^{* *}$ \\
\hline RUS & $0.061^{* * *}$ & $0.008^{* * *}$ & 0.532 & 0.513 & 1.000 & 0.532 & 0.532 \\
\hline ESP & $0.061^{* * *}$ & $0.001^{* * *}$ & 1.000 & $0.002^{* * *}$ & 0.827 & $0.002^{* * *}$ & $0.044^{* * *}$ \\
\hline SWE & 0.662 & 0.532 & 0.684 & $0.442^{*}$ & $0.043^{* * *}$ & $0.331^{*}$ & 1.000 \\
\hline SWI & $0.003^{* * *}$ & $0.001^{* * *}$ & $0.057^{* * *}$ & $0.029^{* * *}$ & $0.004^{* * *}$ & $0.006^{* * *}$ & 1.000 \\
\hline UK & $0.032^{* * *}$ & $0.013^{* * *}$ & $0.156^{* *}$ & $0.156^{* *}$ & $0.052^{* * *}$ & $0.156^{* *}$ & 1.000 \\
\hline US & 0.729 & $0.145^{* *}$ & $0.020^{* * *}$ & 0.581 & 0.729 & $0.165^{* *}$ & 1.000 \\
\hline
\end{tabular}

Notes: Countries: Australia (AUS), Austria (AUT), Belgium (BEL), China (CHI), Cyprus (CYP), Czech Republic (CZE), Denmark (DEN), France (FRA), Finland (FIN), Germany (GER), Greece (GRE), Hong Kong (HK), Hungary (HUN), India (IND), Indonesia (INO), Italy (ITA), Japan (JAP), Malaysia (MAL), Netherlands (NLD), New Zealand (NZ), Norway (NOR), Pakistan (PAK), Philippines (PHI), Poland (POL), Portugal (POR), Romania (ROM), Russia (RUS), Singapore (SIN), South Korea (SK), Spain (ESP), Sweden (SWE), Switzerland (SWI), Taiwan (TAI), Thailand (THA), Turkey (TUR). The MCS p-value are given. ${ }^{*},{ }^{* *}$ and ${ }^{* * *}$ mean that the forecasts are not in $\widehat{\mathcal{M}}_{50 \%}^{*}, \widehat{\mathcal{M}}_{80 \%}^{*}$ and $\widehat{\mathcal{M}}_{90 \%}^{*}$, respectively. 
Table 13: MCS test for out-of-sample forecasting accuracy from EGLS approach.

\begin{tabular}{|c|c|c|c|c|c|c|c|}
\hline Country & $\mathrm{DP}$ & DY & $\mathrm{DE}$ & $\mathrm{EP}$ & PRES & $\mathrm{CVm}$ & STIR \\
\hline AUS & 0.641 & $0.413^{*}$ & 0.641 & 0.641 & 0.641 & 0.641 & 1.000 \\
\hline $\mathrm{CHI}$ & $0.075^{* * *}$ & $0.406^{*}$ & 0.651 & $0.258^{*}$ & 1.000 & 0.876 & - \\
\hline HK & 0.731 & $0.427^{*}$ & $0.387^{*}$ & 1.000 & 0.934 & 0.840 & 0.934 \\
\hline IND & 0.806 & 0.742 & 0.806 & 0.791 & 1.000 & - & - \\
\hline INO & 1.000 & 0.655 & 0.608 & 0.736 & 0.736 & 0.736 & 0.655 \\
\hline JAP & $0.148^{* *}$ & $0.138^{* *}$ & $0.156^{* *}$ & $0.148^{* *}$ & 1.000 & $0.138^{* *}$ & $0.138^{* *}$ \\
\hline SK & 0.446 & $0.180^{* *}$ & 0.859 & 0.527 & $0.180^{* *}$ & 1.000 & $0.003^{* * *}$ \\
\hline MAL & 0.889 & 0.889 & 0.889 & 0.889 & 0.889 & 1.000 & 0.889 \\
\hline $\mathrm{NZ}$ & $0.304^{*}$ & $0.012^{* * *}$ & 0.580 & $0.144^{* *}$ & 1.000 & 0.647 & 0.707 \\
\hline PAK & $0.350^{*}$ & 1.000 & 0.681 & 0.843 & 0.618 & - & - \\
\hline PHI & 0.566 & 0.551 & $0.414^{*}$ & $0.252^{*}$ & 1.000 & 0.566 & 0.677 \\
\hline SIN & 0.896 & 0.873 & 0.758 & 0.657 & 1.000 & 0.896 & - \\
\hline SRI & 0.510 & 0.510 & 0.510 & $0.462^{*}$ & 1.000 & - & - \\
\hline TAI & 0.557 & $0.462^{*}$ & 1.000 & $0.297^{*}$ & 0.557 & $0.462^{*}$ & - \\
\hline THA & $0.434^{*}$ & $0.373^{*}$ & $0.434^{*}$ & $0.434^{*}$ & 1.000 & $0.434^{*}$ & $0.434^{*}$ \\
\hline AUT & $0.144^{* *}$ & $0.041^{* * *}$ & 0.619 & $0.020^{* * *}$ & $0.018^{* * *}$ & 1.000 & $0.106^{* *}$ \\
\hline BEL & 0.943 & 0.969 & 0.912 & 0.936 & 0.929 & 1.000 & 0.969 \\
\hline CYP & 0.568 & 0.568 & 0.568 & 0.568 & 1.000 & 0.568 & - \\
\hline $\mathrm{CZE}$ & 0.650 & 0.650 & 0.650 & 0.650 & 1.000 & 0.637 & $0.158^{* *}$ \\
\hline DEN & 0.560 & 0.560 & 0.560 & 0.560 & 0.526 & 0.560 & 1.000 \\
\hline FIN & $0.367^{*}$ & $0.133^{* *}$ & 0.414 & $0.036^{* * *}$ & $0.001^{* * *}$ & $0.117^{* *}$ & 1.000 \\
\hline FRA & $0.044^{* * *}$ & $0.010^{* * *}$ & $0.116^{* *}$ & $0.014^{* * *}$ & $0.017^{* * *}$ & $0.014^{* * *}$ & 1.000 \\
\hline GER & $0.477^{*}$ & $0.447^{*}$ & $0.447^{*}$ & $0.256^{*}$ & $0.115^{* *}$ & $0.236^{*}$ & 1.000 \\
\hline GRE & $0.042^{* * *}$ & $0.051^{* * *}$ & $0.042^{* * *}$ & $0.051^{* * *}$ & 1.000 & $0.051^{* * *}$ & $0.051^{* * *}$ \\
\hline HUN & $0.001^{* * *}$ & 1.000 & $0.250^{*}$ & $0.052^{* *}$ & $0.005^{* * *}$ & $0.023^{* * *}$ & $0.190^{* *}$ \\
\hline ITA & $0.207^{*}$ & $0.319^{*}$ & 0.735 & $0.112^{* *}$ & $0.001^{* * *}$ & $0.004^{* * *}$ & 1.000 \\
\hline NLD & $0.482^{*}$ & $0.093^{* * *}$ & $0.290^{*}$ & 0.524 & $0.148^{* *}$ & $0.480^{*}$ & 1.000 \\
\hline NOR & $0.362^{*}$ & $0.339^{*}$ & 1.000 & $0.357^{*}$ & $0.062^{* * *}$ & $0.362^{*}$ & $0.482^{*}$ \\
\hline POL & 1.000 & $0.461^{*}$ & 0.867 & $0.319^{*}$ & 0.814 & 0.700 & 0.900 \\
\hline POR & $0.038^{* * *}$ & $0.224^{*}$ & $0.038^{* * *}$ & $0.088^{* * *}$ & 0.504 & $0.045^{* * *}$ & 1.000 \\
\hline ROM & $0.368^{*}$ & $0.140^{* *}$ & 1.000 & $0.177^{* *}$ & 0.528 & $0.207^{*}$ & $0.140^{* *}$ \\
\hline RUS & $0.017^{* * *}$ & $0.471^{*}$ & $0.477^{*}$ & $0.341^{*}$ & 1.000 & $0.477^{*}$ & $0.477^{*}$ \\
\hline ESP & $0.044^{* * *}$ & $0.007^{* * *}$ & 1.000 & $0.001^{* * *}$ & 0.821 & $0.003^{* * *}$ & $0.044^{* * *}$ \\
\hline SWE & 0.696 & 0.534 & 0.710 & $0.428^{*}$ & $0.035^{* * *}$ & $0.257^{*}$ & 1.000 \\
\hline SWI & $0.007^{* * *}$ & $0.001^{* * *}$ & $0.052^{* * *}$ & $0.018^{* * *}$ & $0.002^{* * *}$ & $0.003^{* * *}$ & 1.000 \\
\hline UK & $0.077^{* * *}$ & $0.022^{* * *}$ & $0.282^{*}$ & $0.282^{*}$ & $0.110^{* *}$ & $0.282^{*}$ & 1.000 \\
\hline US & 0.669 & $0.092^{* * *}$ & $0.011^{* * *}$ & $0.469^{*}$ & 0.669 & $0.112^{* *}$ & 1.000 \\
\hline
\end{tabular}

Notes: Countries: Australia (AUS), Austria (AUT), Belgium (BEL), China (CHI), Cyprus (CYP), Czech Republic (CZE), Denmark (DEN), France (FRA), Finland (FIN), Germany (GER), Greece (GRE), Hong Kong (HK), Hungary (HUN), India (IND), Indonesia (INO), Italy (ITA), Japan (JAP), Malaysia (MAL), Netherlands (NLD), New Zealand (NZ), Norway (NOR), Pakistan (PAK), Philippines (PHI), Poland (POL), Portugal (POR), Romania (ROM), Russia (RUS), Singapore (SIN), South Korea (SK), Spain (ESP), Sweden (SWE), Switzerland (SWI), Taiwan (TAI), Thailand (THA), Turkey (TUR). The MCS p-value are given. ${ }^{*},{ }^{* *}$ and ${ }^{* * *}$ mean that the forecasts are not in $\widehat{\mathcal{M}}_{50 \%}^{*}, \widehat{\mathcal{M}}_{80 \%}^{*}$ and $\widehat{\mathcal{M}}_{90 \%}^{*}$, respectively. 
Table 14: Median values of effect size, lower and upper limits before and after the 20082009 Financial Crisis.

\begin{tabular}{lcccccc}
\hline \hline & \multicolumn{3}{c}{ Before 2008 } & \multicolumn{3}{c}{ From 2010 } \\
& Effect & Lower & Upper & Effect & Lower & Upper \\
\hline Asia-Pacific & & & & & & \\
DY & 0.026 & -0.020 & 0.081 & -0.009 & -0.074 & 0.069 \\
DP & 0.045 & -0.008 & 0.079 & 0.0017 & -0.0752 & 0.0666 \\
EP & 0.017 & -0.025 & 0.067 & -0.005 & -0.057 & 0.053 \\
DE & 0.0324 & -0.0212 & 0.0697 & 0.000 & -0.076 & 0.086 \\
PRES & 0.116 & 0.079 & 0.159 & 0.0844 & 0.0407 & 0.1407 \\
CVm & 0.0313 & -0.0080 & 0.0482 & -0.003 & -0.050 & 0.030 \\
STIR & -0.003 & -0.010 & 0.004 & -0.007 & -0.031 & 0.019 \\
\hline Europe & & & & & & \\
DY & 0.011 & -0.026 & 0.051 & -0.013 & -0.065 & 0.054 \\
DP & 0.030 & -0.005 & 0.058 & 0.002 & -0.058 & 0.069 \\
EP & 0.011 & -0.021 & 0.049 & -0.027 & -0.090 & 0.039 \\
DE & 0.024 & -0.022 & 0.071 & 0.032 & -0.033 & 0.106 \\
PRES & 0.103 & 0.067 & 0.143 & 0.082 & 0.015 & 0.142 \\
CVm & 0.005 & -0.026 & 0.058 & -0.010 & -0.051 & 0.027 \\
STIR & -0.012 & -0.021 & -0.004 & -0.011 & -0.035 & 0.009 \\
\hline US & & & & & & \\
DY & 0.054 & 0.011 & 0.098 & 0.060 & -0.047 & 0.167 \\
DP & 0.036 & -0.005 & 0.077 & 0.045 & -0.079 & 0.170 \\
EP & 0.037 & -0.001 & 0.076 & -0.025 & -0.115 & 0.065 \\
DE & 0.005 & -0.072 & 0.082 & 0.045 & -0.049 & 0.139 \\
PRES & 0.092 & 0.051 & 0.133 & 0.061 & 0.022 & 0.100 \\
CVm & 0.076 & -0.016 & 0.168 & -0.051 & -0.116 & 0.013 \\
STIR & -0.001 & -0.006 & 0.003 & -0.021 & -0.211 & 0.169 \\
\hline \hline
\end{tabular}

Notes: The entries for the Asia-Pacific and European stock markets are the median values of 15 and 21 Asia-Pacific and European markets, respectively (not including US). Lower and Upper represent the lower and upper bounds of $95 \%$ confidence interval for effect size estimate $\left(\beta_{1}+\cdots+\beta_{p}\right)$. 